\title{
Article
}

\section{Torque Prediction Model of a CI Engine for Agricultural Purposes Based on Exhaust Gas Temperatures and CFD-FVM Methodologies Validated with Experimental Tests}

\author{
Marco Bietresato*(D), Francesco Selmo, Massimiliano Renzi (D) and Fabrizio Mazzetto (D) \\ Faculty of Science and Technology, Free University of Bozen/Bolzano, Piazza Università 5, \\ I-39100 Bolzano, BZ, Italy; francesco.selmo@natec.unibz.it (F.S.); massimiliano.renzi@unibz.it (M.R.); \\ fabrizio.mazzetto@unibz.it (F.M.) \\ * Correspondence: marco.bietresato@unibz.it; Tel.: +39-0471-017181
}

check for updates

Citation: Bietresato, M.; Selmo, F.; Renzi, M.; Mazzetto, F. Torque Prediction Model of a CI Engine for Agricultural Purposes Based on Exhaust Gas Temperatures and CFD-FVM Methodologies Validated with Experimental Tests. Appl. Sci. 2021, 11, 3892. https://doi.org/ 10.3390/app11093892

Academic Editors: Adrian Irimescu and Timothy Bodisco

Received: 8 March 2021

Accepted: 20 April 2021

Published: 25 April 2021

Publisher's Note: MDPI stays neutral with regard to jurisdictional claims in published maps and institutional affiliations.

Copyright: (c) 2021 by the authors. Licensee MDPI, Basel, Switzerland. This article is an open access article distributed under the terms and conditions of the Creative Commons Attribution (CC BY) license (https:// creativecommons.org/licenses/by/ $4.0 /)$.
Featured Application: A CFD-FVM model of the exhaust pipe of a compression-ignition engine has been used to raise the prediction capabilities of an indirect torque-evaluation model for that engine based on the exhaust gas temperature. The article illustrates in detail also the CFD-FVM model tuning procedure, making use of the Response Surface Methodology and specific procedures based on the exhaust gas temperature at three different locations along the exhaust pipe, detected in some preliminary experimental tests.

Abstract: A truly universal system to optimize consumptions, monitor operation and predict maintenance interventions for internal combustion engines must be independent of onboard systems, if present. One of the least invasive methods of detecting engine performance involves the measurement of the exhaust gas temperature (EGT), which can be related to the instant torque through thermodynamic relations. The practical implementation of such a system requires great care since its torque-predictive capabilities are strongly influenced by the position chosen for the temperaturedetection point(s) along the exhaust line, specific for each engine, the type of installation for the thermocouples, and the thermal characteristics of the interposed materials. After performing some preliminary tests at the dynamometric brake on a compression-ignition engine for agricultural purposes equipped with three thermocouples at different points in the exhaust duct, a novel procedure was developed to: (1) tune a CFD-FVM-model of the exhaust pipe and determine many unknown thermodynamic parameters concerning the engine (including the real EGT at the exhaust valve outlet in some engine operative conditions), (2) use the CFD-FVM results to considerably increase the predictive capability of an indirect torque-detection strategy based on the EGT. The joint use of the CFD-FVM software, Response Surface Method, and specific optimization algorithms was fundamental to these aims and granted the experimenters a full mastery of systems' non-linearity and a maximum relative error on the torque estimations of $2.9 \%$.

Keywords: compression-ignition engine; torque; exhaust gas temperature; thermocouples; CFD; FVM; RSM; indirect estimation; agricultural machines

\section{Introduction}

\subsection{Contextualization of This Study}

Sustainability is one of the master keywords that will lead world development during the next years. Pollution derived from the use of fossil fuels and possible consequent climate changes are two of the most debated arguments nowadays and, because of this, the entire economic sector of internal combustion engines (ICEs), from their production to their use as power units, is one of the most involved in sustainability issues and sustainabilitycompliant strategies. To better frame the problem and its numerous aspects, ICEs are actually the main source of energy for the small-/medium-size cogeneration sector and the 
most common mean to move vehicles and to run industrial and agricultural devices, with traffic being one of the main sources of air pollution in our cities together with residential heating [1,2]. Therefore, improvements brought to ICEs will result in a worldwide positive effect, and this motivates the huge efforts undertaken to make ICEs more "eco-friendly".

This latter aim can be pursued by using many different approaches. Indeed, even though ICEs are a well-established technology and their architecture has reached stability from a technical-evolutionary point of view, advancements are still possible [3]. Radical changes to the engine's architecture are not (economically) feasible today since they would require heavy modifications to consolidated industrial apparatuses (devoted to the massmanufacturing and to servicing of these engines). In fact, just to provide some examples, rotary ICEs (including the Wankel engine) are proposed for very specific applications so as to be quantitatively not influent in the world market, and other, more exotic, architectures (e.g., the opposed-piston engine), although interesting from some points of view, have never passed the hurdle of industrial implementation.

In the described scenario, technical improvements for ICEs are mainly implemented to the exhaust subsystem, to the engine fueling subsystem (including the fuel used to power the engine) and/or the engine performance management subsystem $[4,5]$. The technical solutions regarding the exhaust system are all aimed at further reducing the total amount of air-pollutants emitted; some examples include: particulate filters, catalytic oxidizers and selective catalytic converters (SCRs), whose effectiveness has largely increased over the last years. On the other side, the most promising innovations concerning engine fueling are, essentially, all about new fuel types deriving from renewable resources, able to limit the carbon footprint of the combustion process and, contemporarily, to reduce the pollutants thanks to a more efficient combustion process [6,7]. Engine performance can also be enhanced by optimizing all those detail aspects affecting the correct operation of the engine (i.e., valve openings, timings, injection parameters, spray formation, etc.) [8,9]. The capability of an engine-management system to collect real-time data concerning the engine apparatus is the necessary requirement to pursue the above-listed optimization strategies and adapt their intervention according to the current power requirements. For this reason, modern vehicles are generally equipped with a growing number of electronic onboard devices such as sensors, electronic control units, actuators, electronic-controlled valves etc. that allow the gathering of data about many parameters, their fast processing, and, finally, the use of the elaboration results to actuate the desired engine strategy. An increasing penetration of these technologies on the market would be for sure favored by a quick and progressive replacement policy of old units with newer ones. At this regard, the automotive sector can be taken as a virtuous example. Indeed, the average age of vehicles in the Italian car sector is around 10 years [10], with $68 \%$ of cars being built after 2006, so most of the circulating cars are equipped with devices that can, in some way, collect data and improve their performances thanks to the implementation of closed-loop controls and real-time management-logics. However, due to a mix of many unfavorable factors (weak incentive policies, low financial availability/money supply of stakeholders, unexpressed technical needs by the operators), not all the economic sectors have had or actually have the same opportunities and growth possibilities: the agricultural sector is one of these. For the explained reasons, a common situation even in developed countries sees many agricultural machines that are quite old and that will be kept in use for still many years. For example, the average age of farm tractors in Italy is around 20 years (25 in 2012 [11,12]) and around 700,000 vehicles are more than 33 years old [13,14]. Apart for the total lacking onboard of any modern pollution-abatement system (e.g., EGR, SCR), for these very old vehicles there is no possibility to gather even-simple data on their performance, emissions, or maintenance state (no CAN-BUS system is present: it is based on ISO 11898:2003 standard [15]), so any system-optimization strategy cannot be performed at all.

In the delineated context, the study proposed in this article can be framed in a wider research project by the authors, aimed also at the development of an independent low-cost 
monitoring system able to retrofit and collect data from ICE-powered agricultural machines even not originally equipped with an engine-management/diagnostic system, whichever the reason (high machine age, uneconomic implementation cost of retrofit solutions proposed up to now, too low complexity of the machine itself, etc.). This acquisition system must be designed respecting some compulsory characteristics to properly reach a required level of functionality and usefulness. In the design process it is important to consider that such a system will be mainly used on agricultural vehicles, specifically farm tractors, and the users will be farmers, so it must comply with their needs. Therefore, such a data acquisition system should be, above all, non-invasive or, at least, as low invasive as possible, i.e., it should require minor modifications on the tractor components and a short installation time, not to cause interferences with normal operation of the engine and nor considerable delays to the customer's activities that would discourage its installation. Other mandatory characteristics for it should be: overall robustness (specifically, it should be vibration-, water-, and dust-proof), easiness of use (in terms of: user-friendly interface, easy access to current and stored data, simple or almost-zero maintenance), versatility of application (i.e., it should be suitable for any vehicle and expandable if needed), cost-effectiveness of purchase and maintenance (at least in comparison to the advantages granted by its adoption). Such an engine monitoring system, suitable to the meet the multiple situations that an engine can meet in the agricultural sector, must ensure the acquisition of reliable data related both to the fuel consumption of the vehicles and to the estimation of the possible performance decay that normally occurs with the wear and the prolonged use of the engines. The reliability of the acquired data guarantees the generation of "precise" information, consistent with the nature of the decision-making processes that they will have to support, compatible with the management logic [16]. There are several reasons that make nowadays the research for these types of applications particularly relevant. The first is the need to strengthen the research in the framework of the so-called smart farming (SF) [17-19], which in turn has been stimulated by its links with innovations in the field of Industry 4.0 [20]. For SF, indeed, a growing need is represented by the possibility to automate operational monitoring tasks as much as possible, that is, the management methods by which field processes are carried out, especially with regard to logistics and energy performance. The availability of effective and reliable low-cost tools, adaptable to various situations, even with retrofit adjustments, is a target for any SF application [21]. Secondly, what SF and Industry 4.0 application methodologies have in common is the Knowledge Management 4.0 (KM4.0) [22,23]. Precisely in this area, a requirement of growing interest is the possibility of introducing control methodologies based on predictive maintenance $[24,25]$ also in agriculture as an alternative to the planned maintenance conventionally used in all sectors. Monitoring systems, such as the one that is the final aim of the activities starting from the study proposed here, go toward this direction. Indeed, they allow, also through modeling interpretations, to highlight decay phenomena before the occurrence of critical situations that could bring consumption out of control, and to suggest control or maintenance interventions in advance of the conventionally-planned times.

\subsection{The EGT as a Parameter Useful for Indirectly Measuring the Engine Performances}

The starting point for the development of such an acquisition system is the individuation of the engine parameters to gather and the assessment of the best data-collection methods to employ. Studies dealing with ICEs [26-32] usually focus on the following variables, which are the most representative of an engine and its operating conditions:

- Torque;

- $\quad$ Engine speed;

- Fuel consumption;

- Air requirement;

- Mechanical, thermodynamic, total efficiency;

- Pollutant emissions;

- Lubricant quality; 
- Engine and cooling system temperatures;

- Exhaust gas temperature;

- Sound emissions and vibrations.

Among all these parameters, this article will focus on the exhaust gas temperature (EGT). Indeed, EGT is one of the most meaningful parameters that can be acquired because it is representative of many phenomena occurring inside the engine (specifically, within the combustion chambers), and it is responsible for the correct operation of the devices located along the exhaust pipeline [33]. From a thermodynamic point of view, the EGT can be correlated with: engine torque, power and efficiency, combustion quality, and pollutant emissions. In addition, EGT can rightfully be assumed as an indicator of possible malfunctions involving all previous-listed quantities related to the engine or to the technical devices relying on EGT (the turbocharger, every pollutants-abatement systems: EGR, DPF, SCR, catalytic converters etc.). In particular, the relation between EGT and engine torque $(M)$ is very important, and it is one of the reasons why EGT is such an interesting parameter to be gathered. $M$ is a difficult parameter to be measured if there is no built-in sensor in the studied machine (esp. in the oldest ones), but its direct or indirect acquisition is fundamental as it can describe the engine output better than other parameters. One way to cope with this issue is to derive the torque value from the EGT that can be acquired through the use of thermocouples (from now on: TCs), that are almost inexpensive and very easy to install in comparison to a traditional torque-metering system.

The temperature of the combustion gases reached at the discharge phase of a compression-ignition cycle (i.e., at the outlet of the exhaust valve in the motor head) is directly related (please refer to Figure 1):

(a) To all the thermodynamic transformations composing the cycle before arriving at expansion 3-4, ideally adiabatic (in particular, also to the amount of fuel injected in the considered cycle, during the ideally-isobaric transformation 2-3), and also to the free expansion of combustion gases from point 4 at the exhaust valve opening, ideally isochoric;

(b) To the area included in the loop representing the whole cycle on a $p-V$ plane (pressurevolume), equal to the work per cycle performed by the engine and, hence, to the torque [34].

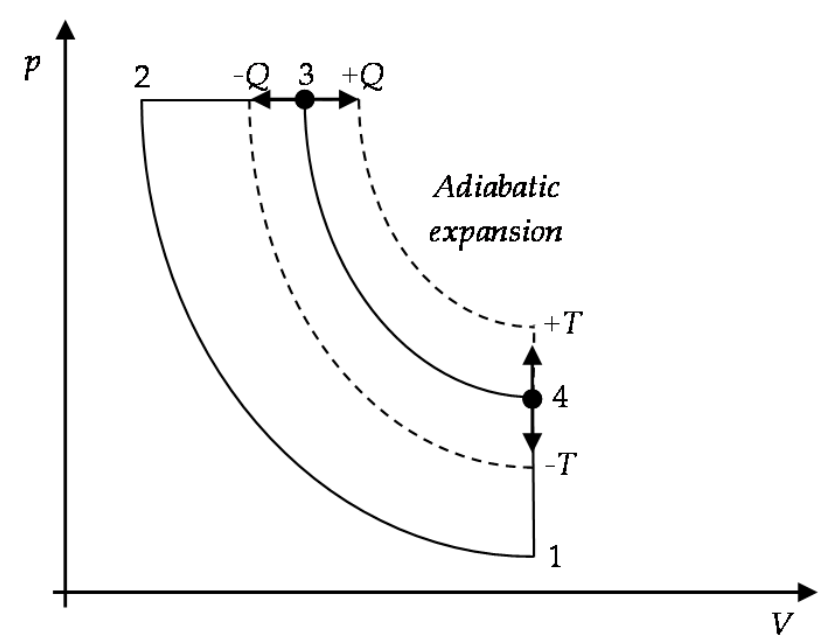

Figure 1. Ideal diesel cycle (i.e., related to a closed system processing an ideal fluid). The different heat $Q$ supplied during the transformation 2-3. Ideally, isobar is responsible for the different workper-cycle expressed by the system and gives different temperatures $T$ at the end of the cycle.

For a given compression ratio $r_{v}$ (constructive-geometric feature of an engine), the values of maximum pressure $p_{2}=p_{3}$ and volume $V_{4}=V_{1}$ that bound geometrically the curve of the adiabatic expansion 3-4 are fixed [34]. Consequently, the work per cycle, hence 
the torque expressed by an engine and the final temperature reached by the operating fluid, which is related to the EGT in an open system $\left(T_{e x} \cong T_{4}\right)$, depends only on the amount of heat supplied to the fluid (Figure 1). Furthermore, in a real thermodynamic cycle, there is also a dependency of the torque from the rotational speed (through the volumetric efficiency). Hence, exploiting the Taylor series, it is possible to approximate the torque as follows [35]:

$$
M=f(n, \Delta T)=b_{0}+b_{1} \cdot \Delta T+b_{2} \cdot \Delta T^{2}+b_{3} \cdot n \cdot \Delta T+b_{4} \cdot n^{2}
$$

(where: $\Delta T$ is the difference between the external air temperature and the EGT, $n$ is the engine rotational speed in $\mathrm{rpm}, b_{0}$ to $b_{4}$ are constants to be determined from some performance tests).

The above-reported equation shows that the torque is a function of a temperature difference (hence: a temperature) and the engine speed, which are parameters that can be measured in an easier way than a direct measurement of $M$. Many studies on engines fueled with traditional and innovative fuels used instead artificial neural networks (ANNs) to predict performance and pollutant emissions [36-39]; however in those works EGT is used to train or check the results and no one uses it to individuate an explicit relation to $M$. In an earlier work [12], it was proposed a methodology to calculate $M$ starting from EGT and engine speed using ANNs, and it was found that this method can predict very well the torque $\left(\mathrm{R}^{2} \cong 0.998\right)$ with a quite short training time $(\leq 5 \mathrm{~s})$ and a reasonable amount of data to be collected for the training and validation phase (about 219 trials).

However, independently from the method employed, the deduction of the torque starting from the EGT strictly relies on the accuracy of the temperature measurement. This experimental implementation can be complicated considering that the EGT, which it is pretended to be used to deduce the torque, is detected in a generic point downstream of the exhaust pipeline, with a thermally-conductive interposed material (i.e., with a thermocouple not in direct contact with the exhaust gas stream). Indeed, due to the many heat-exchange phenomena, which take place along the exhaust gas path (involving all the three heat exchanges modes), depending also on the speed of the exhaust gas (hence by its flow rate), there is no linear proportionality between the detected temperature variations (increments/decrements) and the associated torque variations (increments/decrements) also associated to the time response delays between the torque output and the temperature measurement due to the thermal inertias. As it will be illustrated in this study, the use of a numerical simulation program, such as computational fluid dynamics (CFD) software using the finite volume method (FVM), constitutes a valid and viable tool to preliminary relate the temperature detected at some points the exhaust line $\left(T_{i}\right.$, with $i=1$ to $n$, where $n$ is the number of TCs positioned on the exhaust line), in correspondence with a reduced set of engine speeds (hence, with the associated mass flow rates of the exhaust gas), with the real exhaust gas temperature $T$ in the same cases, thus increasing the accuracy of the general model to predict the torque $M$ :

$$
\left\{\begin{array}{l}
M=a \cdot T_{e x}+b \Rightarrow M=a \cdot T+b \\
T=f\left(T_{i}, \mathrm{CFD}-\mathrm{FVM} \text { model parameters, incl. } n\right)
\end{array}\right.
$$

In this case, even if using an overall model that is linear (the first equation of the two reported above), it is still possible to handle successfully all the non-linearities of such a system using the CFD-FVM in the setup phase before implementing the equations in a possible monitoring system.

Given the importance of EGT, many aspects must be considered to collect the initial data properly and then tune a CFD-FVM model useful to further correct the measurement errors. Proper EGT acquisition relies on a preliminary evaluation of the most adequate instrumentation to be used. Thermal cameras and TCs are the two considered options, each having some advantages and drawbacks: 
- Thermal cameras usually need a proper preparation of the target object (in terms of surface reflectance, smoothness) to ensure a known value of its emissivity; but they have a very high cost if compared to thermocouples and can measure only superficial temperatures; among the advantages, there is the possibility to use them at a set distance from the studied object and to acquire the temperature of many points at the same time;

- TCs are inexpensive, small, robust, can be inserted in some difficult-access points of an engine, even, very close to the exhaust gas flow (using specific solutions, e.g., thermometric wells or "thermowells" to be screwed in dedicated threaded holes), and can be easily connected to a data logging device (output in voltage); on the other side, they need wiring, adaptors, thermometric wells (thus implying the creation of threaded holes on the exhaust pipe), and, finally, each thermocouple can measure the temperature in a single point only.

For what concerns precision, studies show that there is good agreement between the two above-illustrated acquisition techniques [40]. However, for the present case, thermocouples were chosen. The main reason is the need to acquire the EGT also inside the exhaust pipe (at least to have a comparison for the temperatures acquired in other points). Furthermore, thermocouples are more suitable for possible future adoption in an engine monitoring system, thanks to their easier synchronization with other sensors, their robustness, and their cheapness. Nevertheless, the correct use of these sensors is not trivial, and some aspects must be evaluated carefully, as many studies demonstrated [41-44]. Firstly, the right thermocouple-type must be chosen on the basis of the expected absolute value and variation range of the temperature to be measured. Secondly, if thermocouples are used to measure a temperature depending on the EGT (e.g., the surface temperature of the exhaust pipe), the position along the exhaust system must be individuated carefully. Indeed, in such a layout, the TC position is a key element in the measurement process and can highly affect the representativeness of temperature measurements for deducing the related engine performances. The longer the distance of the measuring point from the exhaust valves of an engine, the greater the heat losses due to many (and, sometimes, difficult-to-be-predicted) thermal phenomena. Apart from the position, another concern is about the installation layout and the system adopted to fix the thermocouples (superficial, welded, inside the pipe, with or without a thermometric well) because these choices may significantly affect the final measurement too.

All those above-illustrated aspects determine different fluid dynamic and thermal conditions for the system as its whole, hence directly affect the heat exchange and this is the reason why so many other studies focus on these aspects [45-49]. Things to consider are, for example, the convective exchange coefficients, the emissivity, the thermal diffusivity, and other component properties. Issues to deal with are: the temporal delay of thermal waves due to thermal inertia (especially during non-stationary working conditions) and the presence of a pulsating flow that modifies the internal heat transfer coefficients, thus making the correct EGT estimation from outside the exhaust pipe even more challenging.

\subsection{Aims of This Study}

The purpose of this work is to propose and illustrate a methodology for the indirect assessment of the engine torque. Overall, this methodology should allow to correlate the sensor readings (i.e., thermocouples and other sensors typically embedded in the exhaust line) to the desired output (i.e., the torque) and to ensure the highest representativeness and precision of experimental gatherings. In the same methodology, the joint use of CFD-FVM and RSM is able to maximize the significance of the data coming from some preliminary experimental tests and raise the accuracy of the predictive model. A case study concerning a selected small-scale compression-ignition engine is proposed here, but the presented methodology can be applied also to other engines with different characteristics (e.g., total displacement and number/disposition of cylinders). 
The development of such a methodology has the final aim to develop a self-standing engine monitoring system for agricultural machines and small power generation units, able to acquire reliable data concerning the engine performances and possible performance decays, useful to set up predictive maintenance plans for these machines.

\section{Materials and Methods}

The case study presented here is intended to illustrate a general three-step procedure (Figure 2), which, starting ideally from two experimental tests (in this case corresponding to operating points, named $\mathrm{P}_{0}$ and $\mathrm{P}_{3}$; step 1), thanks to the RSM, allow obtaining a tuned CFDFVM model of the exhaust pipe (step 2.1), useful to identify unknown parameters (step 2.2), formulate considerations on the actual placement of temperature probes, correlate the temperature gatherings with real exhaust gas temperature at the exhaust valve and, hence, with engine performances, and then (step 3) arrive at a mathematical model correlating engine performances with temperatures. This model can be subsequently used on a programmable data acquisition and data processing single-board controller (e.g., Arduino, Raspberry $\mathrm{Pi}$, Lattepanda, or similar). The entire procedure has been verified also on two other operative points inquired during the experimental tests (namely, $\mathrm{P}_{1}$ and $\mathrm{P}_{2}$ ) and its accuracy has been evaluated.

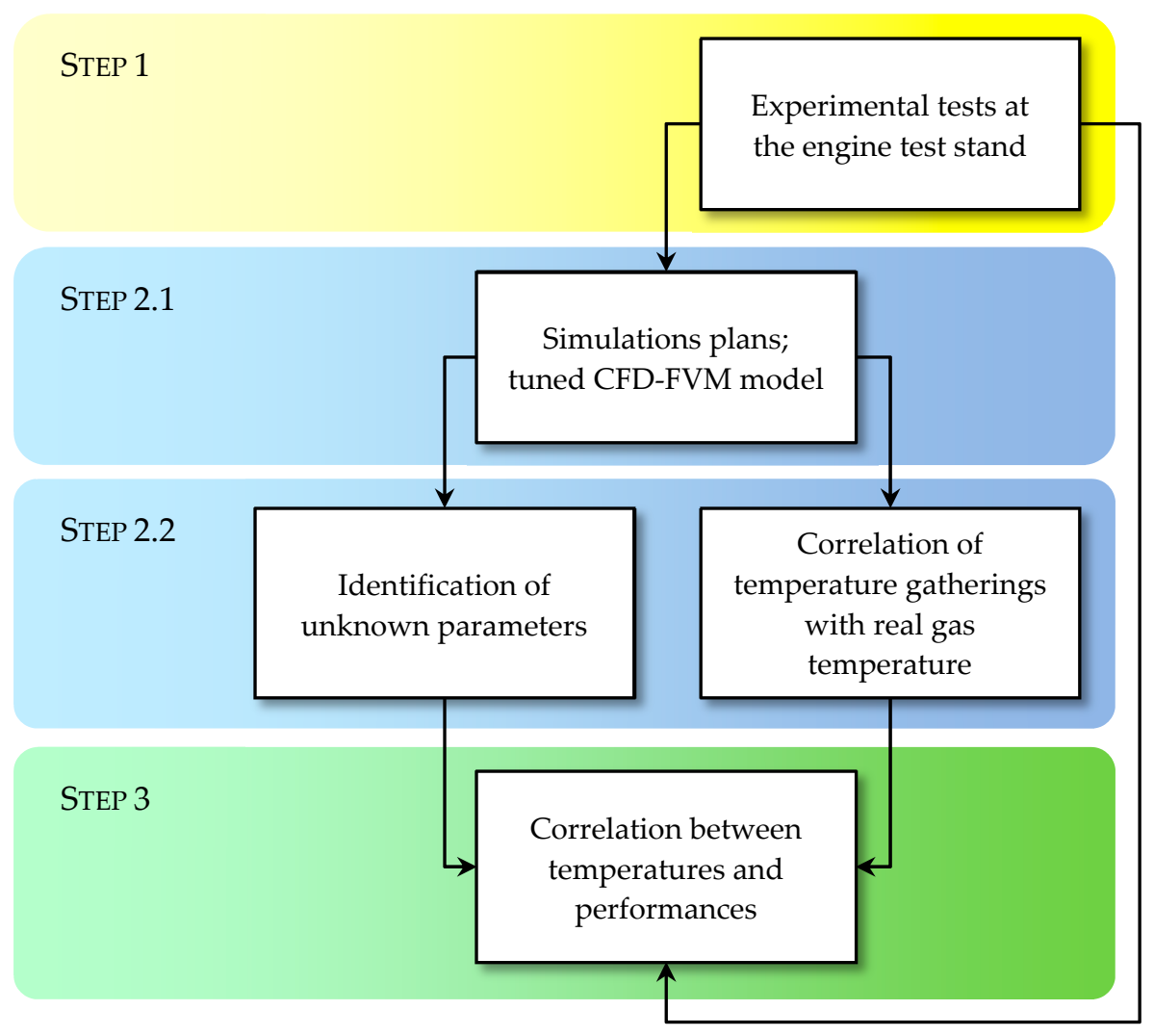

Figure 2. General three-step procedure to be followed to correctly correlate the exhaust gas temperatures of a compression-ignition engine at its exhaust valve with its performances, starting from two tests.

Steps 2.1 and 2.2 were conceptually grouped together in a single step (step 2), as they make use of the same software tools (CFD-FVM, RSM) to perform two sub-procedures related to the estimation of a correct EGT temperature at the exhaust pipe inlet, i.e., at the exhaust valve outlet: 1st sub-procedure about CFD-FVM model tuning, 2nd sub-procedure about fast recalculating the CFD-FVM model tuning parameters.

Step 3 illustrated another algorithm that makes use of the estimated EGT to predict the engine torque ( $3 r d$ sub-procedure about creating the torque prediction model). 


\subsection{Experimental Tests at the Engine Test Stand (Step 1)}

The experimental setup is composed of three main parts (Figure 3):

1. an air-cooled 4-stroke single-cylinder compression-ignition engine (model 15LD225 by Lombardini S.r.l., Reggio Emilia, Italy [50]; Table 1), equipped with a properlydesigned experimental exhaust pipe and with an external instrumented fuel tank (i.e., mounted on a weighting structure);

2. a dynamometric brake (model Braker-Engine 100/E by Soft-Engine S.r.l., Falconara Marittima, Ancona, Italy [51,52]);

3. a set of sensors (some of them installed on the exhaust pipe and the fuel tank, some others embedded in the dynamometer; Table 2) connected to a data logger (model cDAQ 9178 by National Instruments Corp., Austin, TX, USA [52,53]);

Table 1. Main properties of Lombardini 15LD225 compression-ignition engine used in this study.

\begin{tabular}{|c|c|}
\hline Description & Specification \\
\hline $\begin{array}{l}\text { Cylinders (number; configuration; total } \\
\text { displacement; bore } \times \text { stroke) }\end{array}$ & 1; vertical; $224 \mathrm{~cm}^{3} ; 69 \times 60 \mathrm{~mm}$ \\
\hline Fuel-system type & Direct injection, mechanical speed regulator \\
\hline Cooling type & $\begin{array}{l}\text { Forced-air circulation moved by the } \\
\text { bladed flywheel }\end{array}$ \\
\hline Rated power (value; engine speed) & $\begin{array}{c}3.5 \mathrm{~kW} @ 3600 \operatorname{rpm}(80 / 1269 / \mathrm{CEE}-\mathrm{ISO} \\
1585: 2020)\end{array}$ \\
\hline Maximum torque (value; engine speed) & 10.4 Nm@ 2400 rpm \\
\hline Maximum speed & $3600 \mathrm{rpm}$ \\
\hline
\end{tabular}

Table 2. Sensors and datalogger specifications (more details can be found at [52]).

\begin{tabular}{|c|c|c|}
\hline Sensor/Component & Manufacturer, Model & Technical Specification \\
\hline Fuel consumption meter (load cell) & NCB Elettronica, CN/L 7.5 & $\begin{array}{l}\text { Max load } 7.5 \mathrm{~kg}_{\mathrm{f}} \text {, supply voltage } 5-10 \mathrm{~V} \\
\text { rated output } 2 \mathrm{mV} / \mathrm{V} \pm 10 \% \\
\text { combined error }< \pm 0.025 \% \text { f.s. }\end{array}$ \\
\hline Thermocouples & K type & Operating temperature up to $800{ }^{\circ} \mathrm{C}(1073 \mathrm{~K})$ \\
\hline Zirconium-dioxide Lambda probe & Robert Bosch, LSU 4.9 & $\begin{array}{c}\text { Suitable for Diesel/Gasoline } / \mathrm{E} 85, \\
0.65<\lambda<\infty \text {, max operational EGT } 930^{\circ} \mathrm{C}, \\
\text { accuracy } \pm 0.05(@ \lambda=1.7)\end{array}$ \\
\hline Encoder (of the dyno) & Telestar, Minicod-T 1000 5/24 B 1000 & $\begin{array}{l}\text { Input voltage 5-30 V, Sampling speed } \\
100 \mathrm{kHz} \text {, max rotation speed } 6000 \mathrm{rpm}\end{array}$ \\
\hline Torque meter (of the dyno) & Laumas Elettronica, CTL 500 & $\begin{array}{l}\text { Max load } 500 \mathrm{~kg}_{f} \text {, max supply voltage } 15 \mathrm{~V} \\
\text { rated output } 2 \mathrm{mV} / \mathrm{V} \pm 0.1 \%,\end{array}$ \\
\hline Datalogger & National Instruments, C-Daq 9178 & $\begin{array}{l}\text { Input voltage 9-30 V, power } 15 \mathrm{~W} \text {, max } \\
\text { frequency } 1 \mathrm{MHz}\end{array}$ \\
\hline
\end{tabular}

The engine crankshaft is mechanically coupled to the dynamometric brake that applies the desired breaking torque on the engine. The same test stand also leaves the experimenters the possibility to set the engine rotational speed at the desired value.

The original exhaust pipe and the muffler of the engine were both replaced by a specifically designed duct made of AISI 316L stainless steel (Figure 4) and basically composed of two parts:

- A straight pipe (internal diameter: $23 \mathrm{~mm}$; external diameter: $27 \mathrm{~mm}$; length: $250 \mathrm{~mm}$ ), having three different threaded bores designed to seat different sensors (not all used for this study); 
- A pipe-to-head bended connector (internal radius: $36.5 \mathrm{~mm}$; external radius: $63.5 \mathrm{~mm}$; bend angle: $80^{\circ}$ ) necessary to direct the straight part of the pipe upward so that it can be closer to the exhaust gas extraction system of the laboratory.

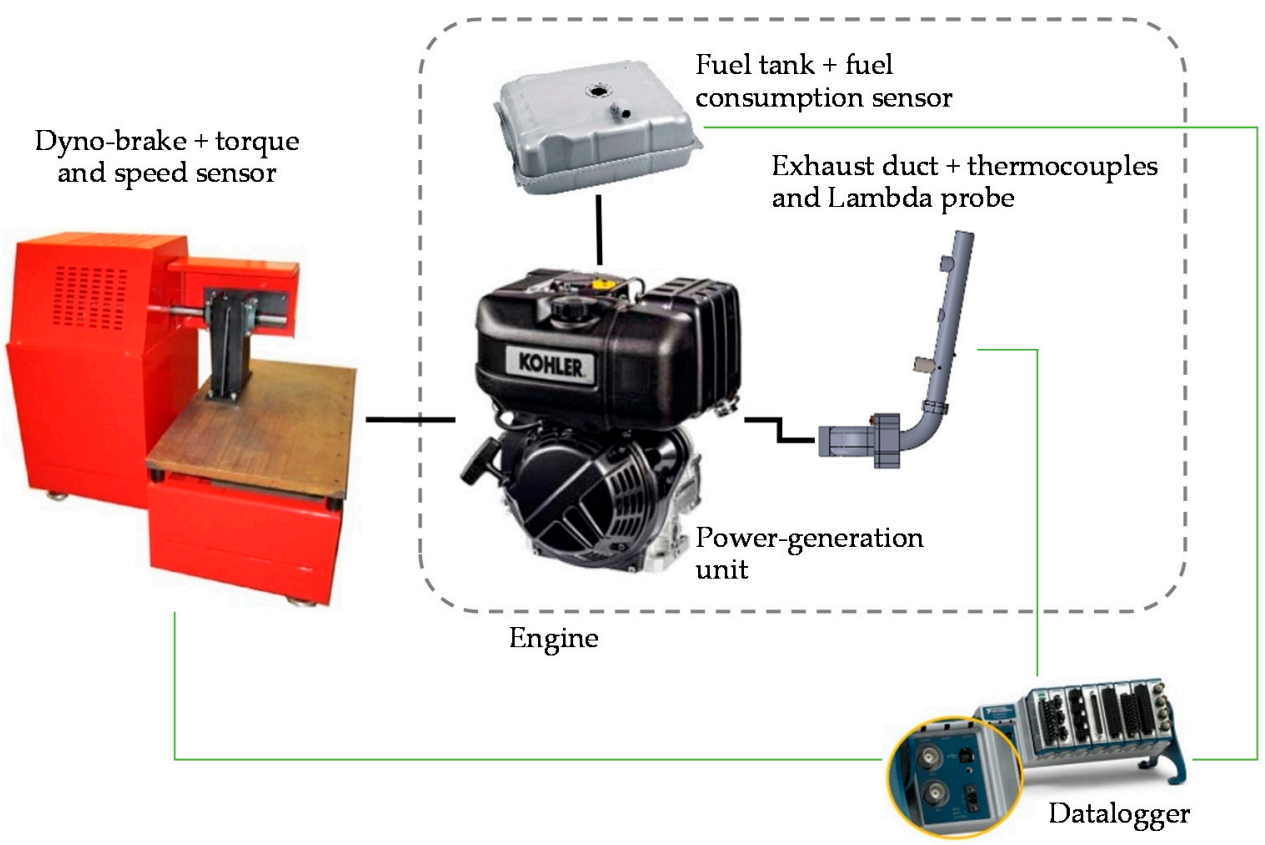

Figure 3. Experimental setup (the dotted rectangle includes the components that are part of the tested engine); black lines represent mechanical/physical connections (shaft, pipes, screw bolts); green lines represent sensor electrical connections for data logging.

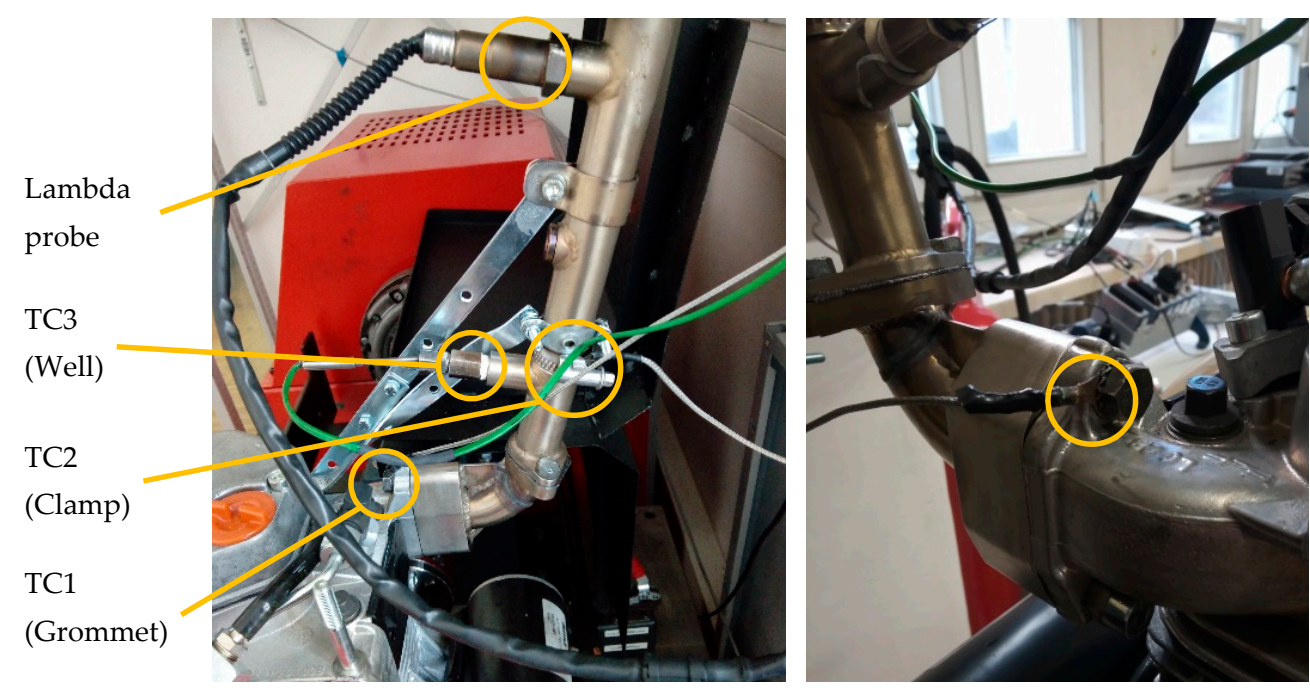

Figure 4. (left) Exhaust duct layout and sensors positioning; (right) close-up view of the TC1 with indicated the position of the tip.

The TCs were applied in three different locations of the experimental exhaust system (see Figure 4 left) with different fixing systems:

- The first TC (TC1) has a grommet that allowed it to be fixed on the bolt of the bended connector holding the exhaust duct on the engine; the tip is close to the grommet external circumference, and, hence, when fixed, it is in contact with the bolt surface and measures the temperature of it (right); this TC is $29.6 \mathrm{~mm}$ apart from the exhaust duct axis, in a position that is $144 \mathrm{~mm}$ distant (equivalent to about 6.3 duct diameters) from the exhaust valve position; 
- $\quad$ The second TC (TC2) has a clamp, which allowed to place the TC with its tip in contact with the exhaust pipe external surface; the clamp was tightened on the exhaust pipe in a position close to the third TC, $70 \mathrm{~mm}$ (3.0 diameters) from the straight tube junction with the connector, $190 \mathrm{~mm}$ (8.3 diameters) from the engine head junction, $334 \mathrm{~mm}$ (14.5 diameters) from the exhaust valve position;

- $\quad$ The third one (TC3) is a TC probe whose tip was inserted into a thermowell screwed in a specific seat on the exhaust pipe, $50 \mathrm{~mm}$ (2.2 diameters) from the straight tube junction with the connector, $170 \mathrm{~mm}$ (7.4 diameters) from the engine head junction, $314 \mathrm{~mm}$ (13.7 diameters) from the exhaust valve position. Therefore, the tip of this TC is spatially inside the exhaust pipe (approximatively at a depth corresponding to the center of the pipe section), and the external surface of the thermowell is in direct contact with the flow of exhaust gases.

In other future applications of the exposed methodology, it is possible to place the TCs in other points, which will be specific to the exhaust line present in the inquired machine (hence, even very different from the one used here). As will be explained later, an experimenter should only take care to individuate the exact positions of the TCs' tips and place them in the CFD-FVM model to proceed with the model calibration procedure that will be explained in the following paragraphs.

For this case study, a total of 4 trials were performed, each one characterized by different conditions of engine load and speed imposed by the dyno, hence determining 4 different operative points for the engine (named from $\mathrm{P}_{0}$ to $\mathrm{P}_{3}$ ). As mentioned before, only two of these operative points are effectively needed for this procedure (in this case, $\mathrm{P}_{0}$ and $\mathrm{P}_{3}$ were chosen), the other two (in this case $\mathrm{P}_{1}$ and $\mathrm{P}_{2}$ ) have been used as verification points and, therefore, in future applications of this procedure they may not be carried out.

The load and speed conditions were kept constant for a minimum of 500 s per trial, so as the detected temperatures ( $T_{1}$ for TC1, $T_{2}$ for TC2, $T_{3}$ for TC 3 ) could reach a constant value, and this value was kept for at least $50 \mathrm{~s}$ (meaning that the system was in a steadystate condition in this last part of the observation period). The room (ambient) temperature was stable around $27^{\circ} \mathrm{C}$ during all the trials.

During each trial, many parameters of interest were collected at the same time: the temperatures from the three TCs, the rotational speed, the torque, the fuel weight, and the value of lambda. The data acquisition interval was set at $10 \mathrm{~s}$ (i.e., the sampling frequency was $0.1 \mathrm{~Hz}$ ) by using a proper program developed within the LABVIEW software environment (by National Instruments Corporation, Austin, Texas, USA [53]) and running on the datalogger. The same program also allowed the calculation of the mobile average on the last 5 acquired values for each measured quantity. Table 3 reports the average values and the expanded uncertainty values (calculated from the instrumental uncertainty and measurement uncertainty using the coverage factor of 1.96 referred to a confidence interval of $95 \%$ [54]) referred to thermal steady-state conditions for the engine per each operative point of the engine. It is worth noting that the highest temperature per each operative point is never the one related to TC1 (i.e., the TC closest to the engine head) because this TC is fixed at a bolt quite distant from the exhaust duct axis and positioned on the external surface of the engine head, so its thermal exposition to the heat of the EG is for sure lower than other TCs.

\subsection{CFD-FVM Model (Step 2.1)}

After the first experimental phase, a computational phase started, making use of the data corresponding to the first operative point $\mathrm{P}_{0}$. In this phase, a list of different cases was simulated (simulations plan) to progressively align the output of an initial CFD-FVM model of the exhaust pipe with reality.

Firstly, a complete 3D model of the exhaust line (Figure 5a), including the exhaust pipe used in the experimental layout (obtained from the drawings used to manufacture the exhaust duct) and part of the exhaust manifold in the engine head (developed from the technical drawings of the engine), was created through the CAD-CAE software suite 
SolidWorks 2020 SP2.0 (by Dassault Systèmes, Vélizy-Villacoublay, France). It is worth noting that, since the goal of such a CFD-FVM model was having the correct path (in terms of length and bends) of the exhaust duct, even in the part inside the engine head, to have the correct flow motion of the exhaust gas, the engine head was carefully modeled only in the exhaust duct starting from some cross-sections found in the technical documentation of the engine. On the contrary, the head was externally modeled with very simple, parallelepiped volumes useful to contain the duct (hence only a "simulacrum" of the engine head was created for this simulation). Therefore, the actual mass and shape, outer surfaces, gaskets and inner cavities of the engine head (including the presence of engine fluids and possible sludge in it) were deliberately not taken into account to have, in the simulation, an element as simple as possible.

Table 3. Experimental data gathered in correspondence at four operative points for the engine (NB: the reported data are the average values, and the expanded uncertainty values referred to steady-state conditions only).

\begin{tabular}{cccccc}
\hline \multirow{2}{*}{ Quantity } & \multirow{2}{*}{ Unit } & \multicolumn{4}{c}{ Engine Operative Point } \\
\cline { 3 - 5 } & & $\mathbf{P}_{\mathbf{0}}$ & $\mathbf{P}_{\mathbf{1}}$ & $\mathbf{P}_{\mathbf{2}}$ & $\mathbf{P}_{\mathbf{3}}$ \\
\hline Torque $(M)$ & $\mathrm{Nm}$ & $8.09( \pm 0.22)$ & $8.15( \pm 0.31)$ & $6.79( \pm 0.25)$ & $5.33( \pm 0.25)$ \\
Rotational Speed $(n)$ & $\mathrm{rpm}$ & $2400( \pm 4)$ & $1970( \pm 13)$ & $2440( \pm 14)$ & $2450( \pm 7)$ \\
\hline$T_{1}$ (grommet) & $\mathrm{K}$ & $450( \pm 2)$ & $448( \pm 2)$ & $438( \pm 2)$ & $430( \pm 2)$ \\
$T_{2}$ (clamp) & $\mathrm{K}$ & $540( \pm 2)$ & $529( \pm 2)$ & $503( \pm 2)$ & $480( \pm 2)$ \\
$T_{3}$ (well) & $\mathrm{K}$ & $680( \pm 2)$ & $673( \pm 2)$ & $633( \pm 2)$ & $591( \pm 2)$ \\
\hline
\end{tabular}

Subsequently, the CAD drawings of this system were imported into the computational package "Flow Simulation" (developed by Mentor Graphics Corporation, part of Siemens group), included in the same software suite SolidWorks, to perform some computational fluid dynamics simulations [55]. This CFD-FVM package is an agile software program sufficiently accurate for industrial applications (hence very widespread in an industrial context), and it was deliberately chosen over other software because of some specific advantages it has for the purposes of this work, not finalized at performing a detailed study on the fluid dynamics of the used exhaust pipe but rather using the CFD-FVM simulation as a tool of a more general procedure. Indeed, "Flow Simulation" has a direct interface with the CAD package, making the model-import operations very quick, simple and error-proof, and setting a simulation is very fast. Notwithstanding some limitations with respect to other more famous CFD-FVM programs, SolidWorks Flow Simulation proved to be more than suitable for the aims of this study, whose novelty is the joint use of some numerical tools, included but not exclusively, a CFD-FVM software. Specifically, the imported geometry was used to bound the spatial domain for the subsequent CFD calculations. In this regard, the geometry of the engine head, far enough from TCs (in particular, TC1) not to influence the results, was properly simplified, not to increase the simulation time uselessly. The spatial domain was then discretized ("meshed") into small control volumes to perform the calculations (Figures $5 \mathrm{~b}$ and 6). The numerical method used to solve the fluid dynamics equations is based on the cell-centered finite volume method (FVM) with the "two-scales wall functions model" [55-57], using two different approaches depending on the mesh refinement level. The resulting mesh (hexcore-type mesh) is composed of a total of 258398 parallelepiped-shaped elements (hexahedrons) for the fluid, having the sides parallel to the three references planes constituting the base trihedron (this is a peculiarity of this software program), and 140900 elements at the fluidsolid interfaces, composed by elements divided geometrically by the solid wall surface (locally approximated by portions of plane), coupling two different calculation domains. The base dimension for the elements was set to $2.500 \mathrm{~mm}$ (i.e., at a refinement level of 2 with reference to the internal scale), with local refinements at the interfaces arriving down to 1.250 and $0.625 \mathrm{~mm}$ (corresponding, respectively, to a refinement level of 3 and 4 for the 
mesh). The refinement of the mesh for the fluid volume near the solid walls is required by this software to create a sufficient number of very small elements able to cope with the inclined solid walls and, hence, to model correctly the boundary layer. The used software applies automatically the Van Driest hypothesis about the mixing length in turbulent boundary layers and the $\mathrm{k}-\varepsilon$ turbulence model [58]. Before running the simulations, mesh independence was proven by raising significantly the number of elements used for the general discretization of fluid and solids domains up to $+44 \%$ and $+37 \%$, respectively, then refining the mesh in correspondence with TC2 and TC 3 in two further subsequent steps, respectively characterized by $+92 \%$ and $+198 \%$ of elements, obtaining in all these cases temperature values for the TCs differing on average by $1.0 \%$ from the reference configuration (1.5\% for TC2).

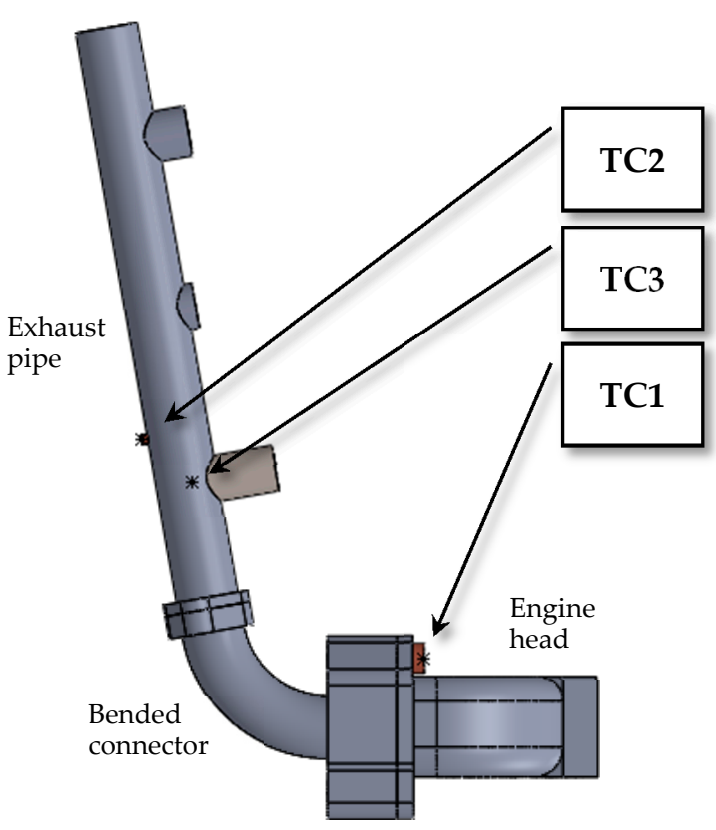

(a)

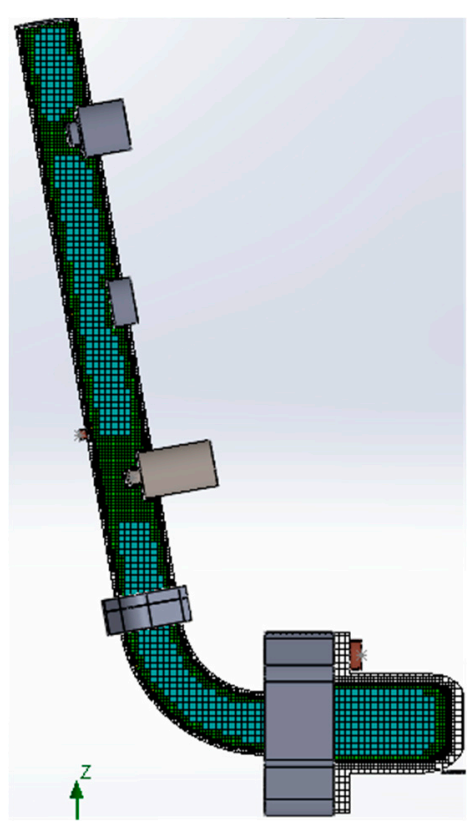

(b)

Figure 5. (a) 3D-CAD lateral view of the exhaust duct geometry; the asterisks indicate the positions of the TCs tips. (b) Used mesh as visible on a section passing through the exhaust pipe axis; the color green is associated to a higher refinement of the base mesh (in light blue) for the fluid. The exhaust pipe inlet is not visible due to the presence of the pipe-to-head connector.

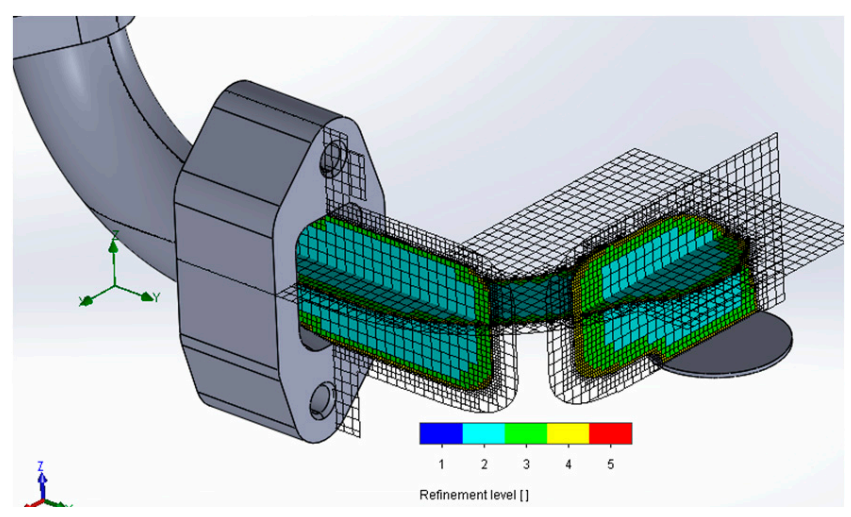

(a)

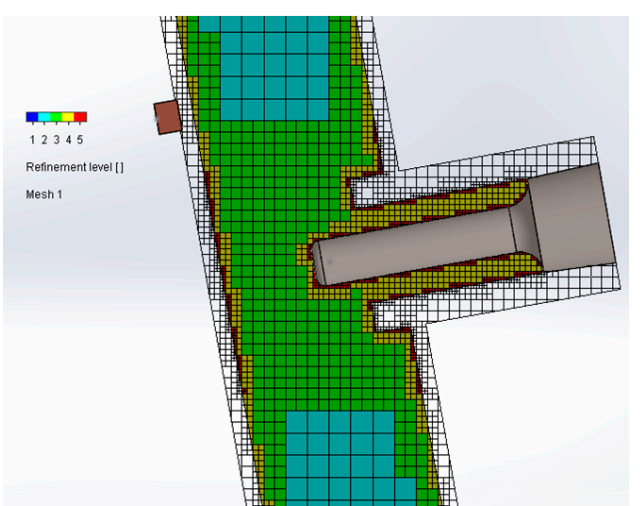

(b)

Figure 6. (a) Close-up view of the mesh for the first part of the exhaust duct, within the pipe-to-head connector and the engine head; the grey circle is the inlet surface of the exhaust line, placed in the same position of the exhaust valve. (b) Close-up view of the mesh in correspondence with the thermowell. 
The exhaust gas was approximated as air [59], and related properties were then recalled by the software library $\left(c_{p} / c_{v}=1.399\right.$; molecular mass $=0.2896 \mathrm{~kg} \cdot \mathrm{mol}^{-1} ; c_{p}$, dynamic density, thermal conductivity variable with the temperature). AISI 316L was chosen as the material for all the parts of the exhaust duct (pipe and connector) and also as material for the engine head as the real material was unknown (see tuning procedure in the following Sections).

As very frequently occurs when setting up numerical simulations, the used software program needs a lot more input parameters than the parameter actually available/known in reality, especially in cases like this one in which a component (the engine head) has been deliberately simplified. For example, although there is the possibility of using internal libraries for the physical properties of the materials involved, often the missing information is just the exact type of material (in the present case for the simulacrum of engine head, different from the actual engine head and, therefore, using also a material non-necessary equal to the real material). Only the full knowledge of all simulation parameters would theoretically result in a perfectly-tuned numerical model. In any other case, there is a need to align the model output(s) with that of the experiments by tuning the unknown parameters. Consequently, a set of unknown parameters has been chosen to act as independent variables to be inquired in their effect on the temperature $T_{1}, T_{2}, T_{3}$ (controlled outputs) and, hence, to be used as tuning parameters for the CFD-FVM model. For all other parameters, the default values proposed by software were kept as valid. Hence, tuning parameters were chosen both according to a literature review and starting from some considerations on the experimental setup used in the first phase (Table 4):

- Radiation and convection (natural or forced) coefficients affect the heat exchange inside and outside the exhaust ducts, whereas material conductivity is responsible for heat conduction through the solid components [42,46];

- The exhaust gas mass flow and the inlet gas temperature influence the amount of discharge thermal power, the fluid dynamics, and the boundary layers inside the pipes influence the heat transfer [43,45,49];

- Thermal contact resistance might affect the heat exchange between different components and between the thermocouples and the metal surfaces where they lay.

Table 4. Reference, upper and lower values for the 8 parameters used in the CFD-FVM model tuning procedure.

\begin{tabular}{cccccc}
\hline Quantity & Abbreviation & Units & Ref. Values & Lower Values & Upper Values \\
\hline Inlet exhaust gas mass flow rate & $\dot{m}_{e x}$ & $\mathrm{~kg} \cdot \mathrm{s}^{-1}$ & 0.004 & 0.002 & 0.008 \\
Inlet exhaust gas temperature & $T$ & $\mathrm{~K}$ & 750 & 600 & 900 \\
$\begin{array}{c}\text { Superficial convective exchange } \\
\text { coefficient (engine head) }\end{array}$ & $H_{h}$ & $\mathrm{~W} \cdot \mathrm{m}^{-2} \cdot \mathrm{K}^{-1}$ & 10 & 5 & 50 \\
$\begin{array}{c}\text { Superficial convective exchange } \\
\text { coefficient (exhaust duct) }\end{array}$ & $H_{e x}$ & $\mathrm{~W} \cdot \mathrm{m}^{-2} \cdot \mathrm{K}^{-1}$ & 10 & 5 & 50 \\
$\quad$ Engine head emissivity & $e_{h}$ & - & 0.65 & 0.30 & 1.00 \\
Exhaust duct surface emissivity & $e_{e x}$ & - & 15 & 5 & 1.00 \\
Head material conductivity & $C_{h}$ & $\mathrm{~W} \cdot \mathrm{m}^{-1} \cdot \mathrm{K}^{-1}$ & 0.00058 & 0.00010 & 0.00120 \\
Contact thermal resistance & $C_{r}$ & $\mathrm{~m}^{2} \cdot \mathrm{K}^{-1} \mathrm{~W}^{-1}$ & & & \\
\hline
\end{tabular}

Once these parameters have been individuated, viable values (reference, upper, lower) were found for each of them, obtaining a set of values used to generate a first simulation plan, i.e., as a starting point for the CFD-FVM model tuning procedure:

- The reference value for the EG mass flow rate $\dot{m}_{e x}$ was calculated, as a first approximation, using the following formula $\left(\lambda=A F R / A F R_{s}\right.$ mean air-fuel equivalence ratio, measured experimentally in the operative point $\mathrm{P}_{0} ; A F R_{S}$ air-fuel ratio under stoichiometric conditions, equal to 14.5 as indicated in [60] for diesel oil; $\dot{m}_{f u e l}$ average fuel consumption in $\mathrm{kg} \cdot \mathrm{s}^{-1}$, measured experimentally in the operative point $\mathrm{P}_{0}$ ):

$$
\dot{m}_{e x}=\left(\lambda \cdot A F R_{s}+1\right) \cdot \dot{m}_{f u e l}
$$


The lower and upper values were calculated, respectively, by dividing and multiplying by two the reference value so as to have a wide range of investigation having the same magnitude order of the reference value;

- The reference value for the EGT at the exhaust pipe inlet (i.e., the approximate temperature immediately after the exhaust valve), namely $T$, has been set at $750 \mathrm{~K}$, a realistic value considering that the gas temperature at the end of the adiabatic expansion phase is typically between 550 and $650{ }^{\circ} \mathrm{C}(823.15-923.15 \mathrm{~K})$ and the temperature of the EGT at the pipe outlet can be $220-250{ }^{\circ} \mathrm{C}(593.15-623.15 \mathrm{~K})$. These data were found in literature in other works using diesel engines of the same size [32,61]; the lower and upper values were calculated from the same references;

- The reference values for the external convection coefficients of the simulacrum of engine head $H_{h}$ and the exhaust duct $H_{e x}$ were estimated starting from formulas referred to natural convection for the considered geometries [62-64]. The lower value is referred to a perfect calm ambient air (i.e., by referring to the situation of some parts of the engine head and exhaust duct, less exposed to the movement of air, as specified later); the higher value is instead calculated considering an enhanced heat dissipation due to a forced-convection phenomenon for some parts of the engine head and of the exhaust gas pipe. Indeed, for the engine head, forced convection could be ascribed to the air-cooling system of the engine (principally insisting on the side of the motor presenting the flywheel), whereas, for the exhaust duct, a forced movement of air could be due to the exhaust gas aspiration system of the laboratory (the aspiration hose inlet was very close to the outlet of the exhaust duct);

- The reference values for the emissivity of the materials (in the engine head simulacrum and the exhaust duct), their conductivity, and the contact thermal resistance were all found in the SolidWorks flow simulation database for the stainless steels with a surface roughness of $1.14 \mu \mathrm{m}$ and a surface pressure of 40-70 atm in the bolted junctions. These values are in full accordance with the literature [65]. Upper and lower values of the emissivity were chosen with reference to other surface finishing and with the aim of having a wide range of possible variations (especially for the head, represented only in a conventional way, as indicated). Upper and lower values of the conductivity and thermal resistance were chosen by looking through other types of iron alloys and different contact pressures in the same database.

Starting from a first $n$-tuple, having all parameters at the reference values of Table 4 ( $n$ tuple nr. 1 of Table 5), other $16 n$-tuples have been generated by varying a single parameter at a time to its maximum and minimum value, hence: 8 parameters with 2 values. The following $10 n$-tuples have been generated by varying 2 parameters at a time (with the exclusion of: convection coefficient referred to the finite elements of the engine head, contact resistance between the different components of the assembly being simulated, the emissivity of the finite elements of the head on the external side). The last $4 n$-tuples of the initial dataset have been generated by again varying 2 parameters at a time (with the exclusion of: convection coefficient referred to the finite elements of the exhaust pipe, contact resistance between the different components of the assembly being simulated, the emissivity of the finite elements of the pipe and head on the external side, the conductivity of the finite elements of the head). Therefore, a total of 31 cases given by 31 different $n$-tuples of parameters $(1+16+10+4)$ have formed the first dataset of simulations (see Section 3.1, Table 5), whose results were used for the model tuning procedure. 
Table 5. Combinations of unknown independent parameters generated from the feasible values of the 8 indicated parameters and temperatures foreseen by the CFD-FVM software.

\begin{tabular}{|c|c|c|c|c|c|c|c|c|c|c|c|}
\hline \multirow[b]{2}{*}{ Nr. } & \multicolumn{8}{|c|}{ Factors (Unknown Independent Parameters) } & \multicolumn{3}{|c|}{ CFD-FVM Results } \\
\hline & $\begin{array}{l}T \\
\mathrm{~K}\end{array}$ & $\begin{array}{c}\dot{m}_{e x} \\
\mathrm{~kg} \cdot \mathrm{s}^{-1}\end{array}$ & $\begin{array}{c}H_{h} \\
\mathbf{W} \cdot \mathbf{m}^{-2} \mathbf{K}^{-1}\end{array}$ & $\begin{array}{c}H_{e x} \\
\mathbf{W} \cdot \mathbf{m}^{-2} \mathbf{K}^{-1}\end{array}$ & $\begin{array}{c}e_{h} \\
-\end{array}$ & $\begin{array}{c}e_{e x} \\
-\end{array}$ & $\begin{array}{c}C_{h} \\
\mathbf{W} \cdot \mathbf{m}^{-1} \cdot \mathbf{K}^{-1}\end{array}$ & $\begin{array}{c}C_{r} \\
\mathrm{~m}^{2} \cdot \mathrm{K} \cdot \mathrm{W}^{-1}\end{array}$ & $\begin{array}{l}T_{1} \\
K\end{array}$ & $\begin{array}{c}T_{2} \\
\mathrm{~K}\end{array}$ & $\begin{array}{l}T_{3} \\
\mathrm{~K}\end{array}$ \\
\hline 1 & 750 & 0.004 & 10 & 10 & 0.65 & 0.65 & 15 & 0.00058 & 550 & 566 & 669 \\
\hline 2 & 900 & 0.004 & 10 & 10 & 0.65 & 0.65 & 15 & 0.00058 & 617 & 637 & 779 \\
\hline 3 & 600 & 0.004 & 10 & 10 & 0.65 & 0.65 & 15 & 0.00058 & 474 & 486 & 551 \\
\hline 4 & 750 & 0.002 & 10 & 10 & 0.65 & 0.65 & 15 & 0.00058 & 517 & 538 & 611 \\
\hline 5 & 750 & 0.008 & 10 & 10 & 0.65 & 0.65 & 15 & 0.00058 & 576 & 593 & 691 \\
\hline 6 & 750 & 0.004 & 50 & 10 & 0.65 & 0.65 & 15 & 0.00058 & 463 & 553 & 658 \\
\hline 7 & 750 & 0.004 & 5 & 10 & 0.65 & 0.65 & 15 & 0.00058 & 566 & 569 & 670 \\
\hline 8 & 750 & 0.004 & 10 & 10 & 0.65 & 0.30 & 15 & 0.00058 & 561 & 591 & 679 \\
\hline 9 & 750 & 0.004 & 10 & 10 & 0.65 & 0.99 & 15 & 0.00058 & 541 & 549 & 661 \\
\hline 10 & 750 & 0.004 & 10 & 10 & 0.65 & 0.65 & 15 & 0.00010 & 555 & 571 & 668 \\
\hline 11 & 750 & 0.004 & 10 & 10 & 0.65 & 0.65 & 15 & 0.00120 & 544 & 560 & 669 \\
\hline 12 & 750 & 0.004 & 10 & 10 & 0.65 & 0.65 & 100 & 0.00058 & 566 & 565 & 668 \\
\hline 13 & 750 & 0.004 & 10 & 10 & 0.65 & 0.65 & 5 & 0.00058 & 537 & 567 & 670 \\
\hline 14 & 750 & 0.004 & 10 & 50 & 0.65 & 0.65 & 15 & 0.00058 & 499 & 473 & 629 \\
\hline 15 & 750 & 0.004 & 10 & 5 & 0.65 & 0.65 & 15 & 0.00058 & 559 & 583 & 676 \\
\hline 16 & 750 & 0.004 & 10 & 10 & 0.99 & 0.65 & 15 & 0.00058 & 541 & 564 & 667 \\
\hline 17 & 750 & 0.004 & 10 & 10 & 0.30 & 0.65 & 15 & 0.00058 & 563 & 570 & 671 \\
\hline 18 & 600 & 0.002 & 10 & 10 & 0.65 & 0.65 & 15 & 0.00058 & 451 & 466 & 515 \\
\hline 19 & 600 & 0.004 & 10 & 10 & 0.65 & 0.99 & 15 & 0.00058 & 469 & 475 & 546 \\
\hline 20 & 600 & 0.004 & 10 & 50 & 0.65 & 0.65 & 15 & 0.00058 & 433 & 413 & 551 \\
\hline 21 & 600 & 0.004 & 10 & 10 & 0.65 & 0.65 & 5 & 0.00058 & 466 & 486 & 551 \\
\hline 22 & 750 & 0.002 & 10 & 10 & 0.65 & 0.99 & 15 & 0.00058 & 508 & 521 & 602 \\
\hline 23 & 750 & 0.002 & 10 & 50 & 0.65 & 0.65 & 15 & 0.00058 & 463 & 443 & 563 \\
\hline 24 & 750 & 0.002 & 10 & 10 & 0.65 & 0.65 & 5 & 0.00058 & 502 & 539 & 612 \\
\hline 25 & 750 & 0.004 & 10 & 50 & 0.65 & 0.99 & 15 & 0.00058 & 495 & 467 & 626 \\
\hline 26 & 750 & 0.004 & 10 & 10 & 0.65 & 0.99 & 5 & 0.00058 & 528 & 549 & 662 \\
\hline 27 & 750 & 0.004 & 10 & 50 & 0.65 & 0.65 & 5 & 0.00058 & 480 & 474 & 631 \\
\hline 28 & 800 & 0.003 & 10 & 10 & 0.65 & 0.65 & 15 & 0.00058 & 559 & 576 & 689 \\
\hline 29 & 750 & 0.003 & 20 & 10 & 0.65 & 0.65 & 15 & 0.00058 & 508 & 548 & 651 \\
\hline 30 & 750 & 0.003 & 40 & 10 & 0.65 & 0.65 & 15 & 0.00058 & 466 & 540 & 646 \\
\hline 31 & 780 & 0.004 & 50 & 10 & 0.65 & 0.65 & 15 & 0.00058 & 474 & 568 & 681 \\
\hline
\end{tabular}

\subsection{Use of RSM to Tune the CFD-FVM Model (Step 2.1)}

The Response Surface Methodology (RSM) was developed by George E. P. Box and K. B. Wilson in 1951 [66,67]; it is a collection of mathematical and statistical techniques based on the fit of data using a polynomial equation [68]. The final goal of every application of RSM is to describe in a mathematically simple way the behavior of a dataset in order to carry out statistical previsions. Specifically, the RSM allows the calculation of an explicit polynomial regression-function of a dependent variable (called "response") from a set of input data concerning a set of independent variables (or "factors"), assumed to be measurable and continuous in their own variation ranges. This function is the best approximation, in a limited validity domain (i.e., the first part of the Taylor series up to the third degree), of an unknown real function [69-72]. In this study, RSM was used to elaborate the effect of different values of parameters on the results and, in particular, to find a combination of values useful to tune the CFD-FVM model (1st sub-procedure about CFD-FVM model tuning). The program Design-Expert v 7.0.0 (Stat-ease inc. Minneapolis, Minnesota, USA; [73]) was used at this purpose.

The model tuning procedure is described hereinafter (see also Figure 7 and Appendix A for details about the RSM):

- $\quad$ The first 31 CFD-FVM simulations were carried out on the basis of the $31 n$-tuples of input parameters, whose values were derived with the procedure described in the 
previous Section, and whose results (temperature values $T_{1}, T_{2}$, or $T_{3}$ ) can be seen in Section 3.1 and constitute the 1st dataset in Figure 7.

- For each of the three measurement positions, thanks to the RSM applied to these first results from the CFD-FVM model, three multilinear mathematical models were found; each model correlates the variation of the unknown parameters with one of the three outputs (temperature values $T_{1}, T_{2}$ or $T_{3}$ ) obtained from the CFD-FVM program (Section 3.1).

- Subsequently, using the internal numerical optimization routine of the RSM program (Appendix A), a list of 30 further parameter combinations (n-tuples of parameters) was generated (it is visible in Section 3.2); on the basis of the predictive numerical models, this list would allow the CFD-FVM to obtain temperatures at the three measurement points as close as possible to the real ones.

- These combinations of parameters were simulated in the CFD-FVM, verifying at the same time the accuracy of the model and the achievement of the experimental temperatures.

- In order to obtain a greater precision for the predictive numerical model and the results obtained at the CFD-FVM, these last 30 simulations were added to the 31 of the initial dataset, obtaining a new dataset (2nd dataset in Figure 7) composed altogether of 61 combinations of parameters, many of which generate an output $\left(T_{1}, T_{2}, T_{3}\right)$ very close to the ideal optimal case (hence with a greater resolution in the neighborhood of the ideal solution).

- $\quad$ By means of the RSM, a second set of three numerical models for $T_{1}, T_{2}, T_{3}$ was then obtained, intentionally kept at low complexity in accordance with the statistical analysis (therefore still multilinear, without increasing in complexity and, therefore, without requiring quadratic models); again, using the numerical optimization routine inside the RSM program (Appendix A), another list of 30 parameter combinations was generated (with a decreasing desirability function; Section 3.4).

- The CFD-FVM verification of these 30 parameter combinations made it possible to identify the best parameter combination for the tuning of the exhaust CFD-FVM model (Section 3.5).

More in detail, every time the RSM was used in the above-illustrated general procedure, after analyzing the data, the software automatically selected for all the models a multilinear model of the 8 variables ( $x_{i}$ with $i=1$ to 8$)$ for each of the investigated responses $y_{j}$, i.e., for the three temperatures $T_{j}$ with $j=1$ to 3 ( $a_{0}$ is the interception coefficient, and $a_{i}$, are the coefficients of the linear terms) [74]:

$$
y_{j}=f\left(x_{i} ; i=1 \text { to } 8\right)=a_{0}+\sum_{i=1}^{8} a_{i} x_{i}=T_{j}
$$

The evaluation of the mathematical models of $T_{1}, T_{2}, T_{3}$ (obtained via RSM in more than a point of the above-described procedure) was carried out, metrologically speaking, in terms of accuracy of the predicted values with respect to the experimental results. This means that the outputs of the associated CFD-FVM model were evaluated in terms of:

- predictive capability as such (in terms of closeness of the CFD-FVM model outputs to the numerical predictions of the RSM in correspondence with each $n$-tuple of setup parameters);

- optimization capability (in terms of closeness of the CFD-FVM model output to the target experimental results in correspondence with each $n$-tuple of setup parameters). 


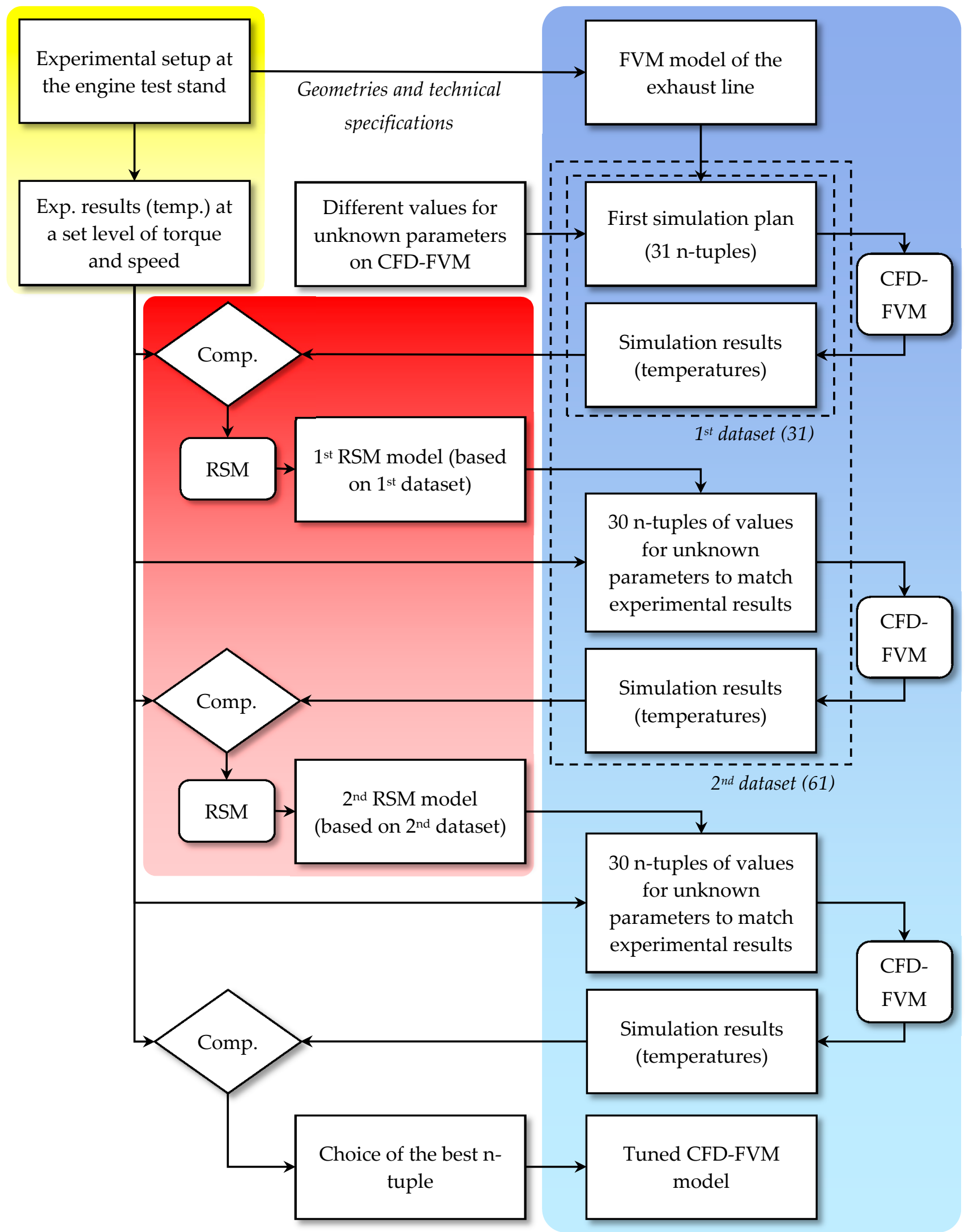

Figure 7. Detailed procedure followed to arrive at a tuned CFD-FVM model as regards the temperature at the three chosen points along the exhaust line (domains of pertinence: yellow-experimentation, blue-numerical simulation, red-numerical analysis/optimization). 


\subsection{Metric to Evaluate the n-Tuples Proposed by RSM-Based Optimization on the Basis of the CFD-FVM Results}

The evaluation of the many $n$-tuples indicated by the RSM-based optimization procedure (and, in particular, the individuation of the best $n$-tuple) has been performed on the basis of the values of the temperatures resulting from the CFD-FVM simulations, after the CFD-FVM model has been run with the independent parameters set as the values of the $n$-tuples. At this purpose, a merit function $M_{f}$, useful to rank the $n$-tuples using a single value, has been defined, starting from the following two quantities:

- the mean of absolute percentage errors $\left(\varepsilon_{\text {mean }, a b s}\right)$, defined as the arithmetic mean of the absolute value of relative errors (expressed as percentages) of the difference between each value obtained from the CFD-FVM simulations $T_{i}$ from the target value $T_{\text {target }, i}$ for the same temperature;

- $\quad$ the maximum absolute percentage error $\left(\varepsilon_{\max , a b s}\right)$, defined as the greatest among the absolute values of relative errors (expressed as percentages) of the difference between each value obtained from the CFD-FVM simulations $T_{i}$ from the target value $T_{\text {target }, i}$ for the same temperature;

If each couple $\left(\varepsilon_{\text {mean }, a b s} ; \varepsilon_{\text {max abs }}\right)$ is represented as a point on a proper Cartesian plane, a merit function, useful to evaluate the adherence of a CFD-FVM simulation to the reality by accounting both the described quantities at the same time, can be defined as the inverse of the Euclidean distance of these points from the origin:

$$
\left\{\begin{array}{l}
\varepsilon_{\text {mean }, a b s}=\frac{1}{3} \cdot \sum_{i=1}^{3}\left|100 \cdot \frac{T_{i}-T_{\text {target }, i}}{T_{\text {target }, i}}\right| \\
\varepsilon_{\text {max }, a b s}=\max \left\{i=1: 3 ;\left|100 \cdot \frac{T_{i}-T_{\text {target }, i}}{T_{\text {target }, i}}\right|\right\}
\end{array} \Rightarrow M_{f}=100 \cdot\left(\varepsilon_{\text {mean }, a b s}^{2}+\varepsilon_{\text {max }, a b s}^{2}\right)^{-\frac{1}{2}}\right.
$$

If the target values are the reference values from the experimentation as referred to the operative point $\mathrm{P}_{0}\left(450,540\right.$, and $\left.680{ }^{\circ} \mathrm{C}\right)$, the merit function $M_{f}$ is a valid aid to individuate the best $n$-tuple to tune the FVM model so as it is as close as possible to the reality in terms of outputs. The higher the value assumed by $M_{f}$, the more suitable is the $n$-tuple for this purpose (i.e., the better the adherence of the associated simulation to reality). Considering again the graphical representation of each couple $\left(\varepsilon_{\text {mean,abs }} ; \varepsilon_{\text {max abs }}\right)$ as a point on a Cartesian plane, all points are placed in the first quadrant above the bisector (because $\varepsilon_{\text {mean,abs }} \leq \varepsilon_{\text {max abs }}$ always) and below the line $\varepsilon_{\text {max }, a b s}=3 \cdot \varepsilon_{\text {mean,abs }}$ (because the maximum cannot be over 3 times the mean of absolute percentage errors, as there are only positive absolute values in the two indicated quantities). As $M_{f}$ is inversely related to the Euclidean distance of each of these points from the origin of the axes, by a geometrical-topological point of view, the best $n$-tuple is individuated by the point closest to the origin.

If a value of 5 percentage points were considered as the threshold of technical acceptability for both the mean of absolute percentage errors $\left(\varepsilon_{\text {mean }, a b s}\right)$ and the maximum absolute percentage error $\left(\varepsilon_{\max , a b s}\right)$, the feasible $n$-tuples will have the representative points all within the triangle ABO (evidenced in Figure 8); the merit function at the upper boundary segment $\mathrm{AB}$ will have a value spanning from $100 /(50)^{0.5}=14.14$ of point $\mathrm{A}$ (if $\varepsilon_{\text {mean }, a b s}$ $\left.=\varepsilon_{\text {max }, a b s}=5\right)$ to $100 /(27.78)^{0.5}=18.97$ of point $\mathrm{B}\left(\right.$ if $\varepsilon_{\text {mean }, a b s}=5 / 3=1.67$ and $\left.\varepsilon_{\text {max }, a b s}=5\right)$. The value of 14.14 must therefore be considered as the minimum reference value for the merit function. 


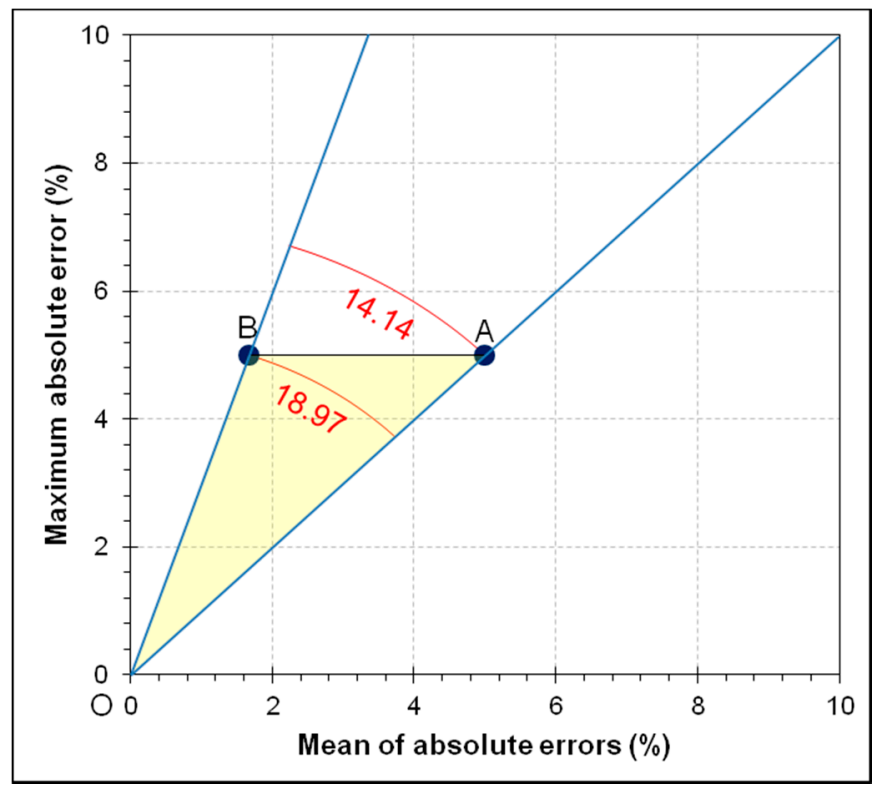

Figure 8. Cartesian plan used to place the points representative of the accuracy reached with each $n$-tuple; the yellow area is defined by imposing an upper threshold of 5 percentage points for both the quantities at the axes; the values of the merit function along the red arcs passing through points $\mathrm{A}$ and $\mathrm{B}$ are written in red.

\section{Results and Discussion}

3.1. First Set of RSM Models for the Exhaust Gas Temperatures Obtained from the CFD-FVM Model

According to the RSM software suggestions based on the number of independent factors and their inferred influence on the CFD-FVM responses in correspondence to the $31 n$-tuples of the first dataset (Table 5), the only possible type of response surface model for each of the considered responses (i.e., the three temperatures in this case) can only be a linear model. An ANOVA analysis for each response (reported in Appendix B) allowed evidencing the statistically significant factors for each of the three responses $[67,75]$, performing a backward elimination-process of the non-significant terms till arriving to have three multilinear regression models with only the statistically significant factors (6 for $T_{1}, 5$ for $T_{2}, 3$ for $T_{3}$, Tables 6 and 7 ).

Table 6. Factors influencing each of the three responses (indicated by the black spot $\bullet$ ) as resulting from the ANOVA performed on the CFD-FVM results.

\begin{tabular}{ccccccccc}
\hline \multirow{2}{*}{ Response } & \multicolumn{8}{c}{ Factors } \\
\cline { 2 - 8 } & $T$ & $\dot{m}_{\boldsymbol{e x}}$ & $\boldsymbol{H}_{\boldsymbol{h}}$ & $\boldsymbol{H}_{\boldsymbol{e x}}$ & $\boldsymbol{e}_{\boldsymbol{h}}$ & $\boldsymbol{e}_{\boldsymbol{e x}}$ & $\boldsymbol{C}_{\boldsymbol{h}}$ & $\boldsymbol{C}_{\boldsymbol{r}}$ \\
\hline$T_{1}$ & $\bullet$ & $\bullet$ & $\bullet$ & $\bullet$ & - & $\bullet$ & $\bullet$ & - \\
$T_{2}$ & $\bullet$ & $\bullet$ & $\bullet$ & $\bullet$ & - & $\bullet$ & - & - \\
$T_{3}$ & $\bullet$ & $\bullet$ & - & $\bullet$ & - & - & - & - \\
\hline
\end{tabular}

Table 7. Multilinear regression models for the three temperatures elaborated on the basis of the first dataset (31 cases).

\begin{tabular}{ccc}
\hline Model & $\mathbf{R}^{2}$ & ${\text { Adj } \mathbf{R}^{2}}^{2}$ \\
\hline$T_{1}=+193.93281+0.46572 \cdot T+12,005.37018 \cdot \dot{m}_{e x}-2.14127 \cdot H_{h}-1.25159 \cdot H_{e x}-26.00263 \cdot e_{e x}+0.30761 \cdot C_{h}$ & 0.9707 & 0.9634 \\
\hline$T_{2}=+211.42148+0.48917 \cdot T+10,909.56897 \cdot \dot{m}_{e x}-0.31697 \cdot H_{h}-2.19402 \cdot H_{e x}-50.45951 \cdot e_{e x}$ & 0.9883 & 0.9859 \\
\hline$T_{3}=+62.28571+0.71706 \cdot T+17,416.25541 \cdot \dot{m}_{e x}-0.83049 \cdot H_{e x}$ & 0.9391 & 0.9323 \\
\hline
\end{tabular}




\subsection{Additional Set of 30 Possible n-Tuples to Match the Experimental Results}

Thanks to the internal numerical optimization routine of the RSM software, it has been possible to generate further $30 n$-tuples of values for the unknown parameters, which, according to the above-reported regression models, should be able to match the CFDFVM model with the experimental results. These considered $30 n$-tuples are only the $n$-tuples with the highest value of desirability (see Table 8). The same table also shows the numerical estimates for the three temperatures, calculated with the RSM models stated above. It is worth noting that, due to the linearization of the phenomena made by the RSM models, some estimates for the three temperatures can correspond to a physically impossible situation where $T \leq T_{3}$ (cases nr. 11,22, 23). As the CFD-FVM software operates instead according to rigorous physical principles, these $n$-tuples would originate for sure high prediction errors (in particular in correspondence with $T_{3}$ ), but, as a general rule, they should be, however, simulated to have some further points useful to correct the RSM models.

Table 8. Combinations of unknown independent parameters suggested by RSM optimization procedure, together with the outputs in terms of desirability ad foreseen temperature in the three measuring points.

\begin{tabular}{|c|c|c|c|c|c|c|c|c|c|c|c|c|}
\hline \multirow{2}{*}{ Nr. } & \multicolumn{8}{|c|}{ Factors (Unknown Independent Parameters) } & \multicolumn{4}{|c|}{$\begin{array}{l}\text { RSM Optimization } \\
\text { Procedure Outputs }\end{array}$} \\
\hline & $\begin{array}{l}T \\
\mathrm{~K}\end{array}$ & $\dot{m}_{e x}$ & $\begin{array}{c}H_{h} \\
\mathbf{W} \cdot \mathbf{m}^{-2} \mathrm{~K}^{-1}\end{array}$ & $\begin{array}{c}H_{e x} \\
\mathbf{W} \cdot \mathbf{m}^{-2} \mathbf{K}^{-1}\end{array}$ & $e_{h}$ & $e_{e x}$ & $\begin{array}{c}C_{h} \\
\mathbf{W} \cdot \mathbf{m}^{-1} \cdot \mathrm{K}^{-1}\end{array}$ & $\begin{array}{c}C_{r} \\
\mathbf{m}^{2} \cdot \mathbf{K} \cdot \mathbf{W}^{-1}\end{array}$ & $\begin{array}{c}\text { Desirability } \\
-\end{array}$ & $\begin{array}{l}T_{1} \\
\mathrm{~K}\end{array}$ & $\begin{array}{l}T_{2} \\
\mathrm{~K}\end{array}$ & $\begin{array}{l}T_{3} \\
\mathrm{~K}\end{array}$ \\
\hline 1 & 815 & 0.003 & 50 & 24 & 0.68 & 0.69 & 5 & 0.00095 & 0.9873 & 456 & 540 & 679 \\
\hline 2 & 816 & 0.003 & 50 & 17 & 0.30 & 0.91 & 5 & 0.00034 & 0.9870 & 460 & 544 & 686 \\
\hline 3 & 830 & 0.002 & 50 & 22 & 0.65 & 0.77 & 10 & 0.00101 & 0.9868 & 453 & 536 & 674 \\
\hline 4 & 844 & 0.002 & 50 & 28 & 0.58 & 0.59 & 9 & 0.00110 & 0.9857 & 456 & 539 & 679 \\
\hline 5 & 856 & 0.002 & 50 & 37 & 0.30 & 0.32 & 5 & 0.00120 & 0.9830 & 456 & 539 & 680 \\
\hline 6 & 838 & 0.003 & 50 & 36 & 1.00 & 0.32 & 13 & 0.00040 & 0.9797 & 464 & 543 & 686 \\
\hline 7 & 707 & 0.008 & 50 & 32 & 0.67 & 0.34 & 6 & 0.00120 & 0.9729 & 465 & 541 & 682 \\
\hline 8 & 765 & 0.005 & 49 & 14 & 0.49 & 1.00 & 19 & 0.00010 & 0.9721 & 468 & 543 & 686 \\
\hline 9 & 763 & 0.005 & 50 & 17 & 1.00 & 0.87 & 26 & 0.00114 & 0.9715 & 466 & 542 & 682 \\
\hline 10 & 833 & 0.003 & 50 & 36 & 0.92 & 0.32 & 32 & 0.00113 & 0.9674 & 467 & 541 & 682 \\
\hline 11 & 678 & 0.008 & 50 & 11 & 0.79 & 1.00 & 23 & 0.00010 & 0.9662 & 466 & 540 & 679 \\
\hline 12 & 716 & 0.006 & 50 & 12 & 0.30 & 1.00 & 33 & 0.00012 & 0.9634 & 461 & 534 & 670 \\
\hline 13 & 840 & 0.002 & 50 & 24 & 0.42 & 0.72 & 44 & 0.00096 & 0.9626 & 467 & 539 & 680 \\
\hline 14 & 847 & 0.002 & 50 & 30 & 0.99 & 0.50 & 56 & 0.00050 & 0.9531 & 472 & 541 & 680 \\
\hline 15 & 740 & 0.006 & 50 & 19 & 0.98 & 0.85 & 44 & 0.00040 & 0.9520 & 471 & 538 & 682 \\
\hline 16 & 815 & 0.003 & 50 & 34 & 0.34 & 0.30 & 56 & 0.00010 & 0.9441 & 469 & 537 & 671 \\
\hline 17 & 810 & 0.003 & 50 & 14 & 0.30 & 1.00 & 85 & 0.00029 & 0.9378 & 483 & 543 & 684 \\
\hline 18 & 750 & 0.005 & 50 & 14 & 1.00 & 0.95 & 79 & 0.00106 & 0.9357 & 478 & 538 & 676 \\
\hline 19 & 773 & 0.004 & 50 & 13 & 0.30 & 1.00 & 84 & 0.00021 & 0.9343 & 478 & 538 & 675 \\
\hline 20 & 702 & 0.008 & 50 & 31 & 1.00 & 0.34 & 63 & 0.00108 & 0.9336 & 482 & 541 & 679 \\
\hline 21 & 838 & 0.003 & 50 & 50 & 0.30 & 0.32 & 10 & 0.00120 & 0.9335 & 445 & 512 & 674 \\
\hline 22 & 654 & 0.008 & 50 & 6 & 0.71 & 1.00 & 65 & 0.00010 & 0.9241 & 474 & 539 & 666 \\
\hline 23 & 645 & 0.008 & 50 & 6 & 1.00 & 0.78 & 20 & 0.00010 & 0.9202 & 462 & 546 & 659 \\
\hline 24 & 684 & 0.007 & 50 & 9 & 0.31 & 1.00 & 88 & 0.00011 & 0.9182 & 479 & 536 & 667 \\
\hline 25 & 685 & 0.008 & 50 & 18 & 0.31 & 0.75 & 91 & 0.00041 & 0.9171 & 488 & 541 & 678 \\
\hline 26 & 795 & 0.004 & 50 & 30 & 1.00 & 1.00 & 43 & 0.00059 & 0.9144 & 455 & 512 & 677 \\
\hline 27 & 824 & 0.002 & 40 & 15 & 0.45 & 1.00 & 56 & 0.00119 & 0.9087 & 488 & 540 & 676 \\
\hline 28 & 851 & 0.002 & 33 & 35 & 0.70 & 0.64 & 5 & 0.00120 & 0.8998 & 485 & 530 & 678 \\
\hline 29 & 846 & 0.002 & 29 & 39 & 0.87 & 0.30 & 5 & 0.00119 & 0.8855 & 495 & 537 & 671 \\
\hline 30 & 848 & 0.002 & 38 & 31 & 0.46 & 1.00 & 31 & 0.00120 & 0.8842 & 476 & 518 & 679 \\
\hline
\end{tabular}

These $n$-tuples were subsequently inquired via the CFD-FVM software. The results coming from the simulation have been collected in the following table (Table 9), together with the absolute and percentage errors (related to the experimental target values), and the above-defined metrics, based on these errors, used to evaluate each $n$-tuple. Figure 9 gives a graphical representation of the evaluation metrics. 
Table 9. Evaluation of each $n$-tuple with reference to the experimental target values for the temperatures.

\begin{tabular}{|c|c|c|c|c|c|c|c|c|c|c|c|c|}
\hline \multirow{2}{*}{ Nr. } & \multicolumn{3}{|c|}{$\begin{array}{c}\text { Simulation Outputs } \\
\text { (CFD-FVM) }\end{array}$} & \multicolumn{3}{|c|}{ Absolute Errors } & \multicolumn{3}{|c|}{ Percentage Errors } & \multicolumn{3}{|c|}{ Evaluation Metrics } \\
\hline & $\begin{array}{l}T_{1} \\
\mathrm{~K}\end{array}$ & $\begin{array}{c}T_{2} \\
\mathrm{~K}\end{array}$ & $\begin{array}{l}T_{3} \\
\mathrm{~K}\end{array}$ & $\begin{array}{c}\Delta T_{1} \\
\mathrm{~K}\end{array}$ & $\begin{array}{c}\Delta T_{2} \\
\mathrm{~K}\end{array}$ & $\begin{array}{c}\Delta T_{3} \\
\mathbf{K}\end{array}$ & $\begin{array}{c}\Delta T_{1} \\
\%\end{array}$ & $\begin{array}{c}\Delta T_{2} \\
\%\end{array}$ & $\begin{array}{c}\Delta T_{3} \\
\%\end{array}$ & $\begin{array}{c}\text { Mean abs. Err. } \\
\%\end{array}$ & $\begin{array}{c}\text { Max abs. Err. } \\
\%\end{array}$ & $\begin{array}{c}M_{f} \\
-\end{array}$ \\
\hline 1 & 431 & 522 & 671 & -19 & -18 & -9 & -4.2 & -3.3 & -1.3 & 3.0 & 4.2 & 19.4 \\
\hline 2 & 462 & 558 & 685 & +12 & +18 & +5 & +2.7 & +3.3 & +0.7 & 2.2 & 3.3 & 24.9 \\
\hline 3 & 425 & 512 & 618 & -25 & -28 & -62 & -5.6 & -5.2 & -9.1 & 6.6 & 9.1 & 8.9 \\
\hline 4 & 422 & 509 & 621 & -28 & -31 & -59 & -6.2 & -5.7 & -8.7 & 6.9 & 8.7 & 9.0 \\
\hline 5 & 411 & 501 & 624 & -39 & -39 & -56 & -8.7 & -7.2 & -8.2 & 8.0 & 8.7 & 8.5 \\
\hline 6 & 485 & 605 & 716 & 35 & +65 & +36 & +7.8 & +12.0 & +5.3 & 8.4 & 12.0 & 6.8 \\
\hline 7 & 432 & 520 & 635 & -18 & -20 & -45 & -4.0 & -3.7 & -6.6 & 4.8 & 6.6 & 12.3 \\
\hline 8 & 490 & 550 & 666 & +40 & +10 & -14 & +8.9 & +1.9 & -2.1 & 4.3 & 8.9 & 10.1 \\
\hline 9 & 458 & 535 & 662 & +8 & -5 & -18 & +1.8 & -0.9 & -2.6 & 1.8 & 2.6 & 31.3 \\
\hline 10 & 449 & 508 & 671 & -1 & -32 & -9 & -0.2 & -5.9 & -1.3 & 2.5 & 5.9 & 15.6 \\
\hline 11 & 471 & 533 & 619 & +21 & -7 & -61 & +4.7 & -1.3 & -9.0 & 5.0 & 9.0 & 9.7 \\
\hline 12 & 483 & 536 & 638 & +33 & -4 & -42 & +7.3 & -0.7 & -6.2 & 4.8 & 7.3 & 11.4 \\
\hline 13 & 450 & 513 & 621 & 0 & -27 & -59 & +0.0 & -5.0 & -8.7 & 4.6 & 8.7 & 10.2 \\
\hline 14 & 453 & 508 & 619 & +3 & -32 & -61 & +0.7 & -5.9 & -9.0 & 5.2 & 9.0 & 9.7 \\
\hline 15 & 474 & 532 & 651 & +24 & -8 & -29 & +5.3 & -1.5 & -4.3 & 3.7 & 5.3 & 15.4 \\
\hline 16 & 480 & 516 & 662 & +30 & -24 & -18 & +6.7 & -4.4 & -2.6 & 4.6 & 6.7 & 12.4 \\
\hline 17 & 486 & 537 & 671 & +36 & -3 & -9 & +8.0 & -0.6 & -1.3 & 3.3 & 8.0 & 11.6 \\
\hline 18 & 462 & 534 & 656 & +12 & -6 & -24 & +2.7 & -1.1 & -3.5 & 2.4 & 3.5 & 23.3 \\
\hline 19 & 490 & 541 & 664 & +40 & +1 & -16 & +8.9 & +0.2 & -2.4 & 3.8 & 8.9 & 10.3 \\
\hline 20 & 455 & 516 & 630 & +5 & -24 & -50 & +1.1 & -4.4 & -7.4 & 4.3 & 7.4 & 11.7 \\
\hline 21 & 429 & 483 & 665 & -21 & -57 & -15 & -4.7 & -10.6 & -2.2 & 5.8 & 10.6 & 8.3 \\
\hline 22 & 470 & 532 & 603 & +20 & -8 & -77 & +4.4 & -1.5 & -11.3 & 5.7 & 11.3 & 7.9 \\
\hline 23 & 462 & 535 & 599 & +12 & -5 & -81 & +2.7 & -0.9 & -11.9 & 5.2 & 11.9 & 7.7 \\
\hline 24 & 481 & 532 & 621 & +31 & -8 & -59 & +6.9 & -1.5 & -8.7 & 5.7 & 8.7 & 9.6 \\
\hline 25 & 475 & 528 & 622 & +25 & -12 & -58 & +5.6 & -2.2 & -8.5 & 5.4 & 8.5 & 9.9 \\
\hline 26 & 463 & 507 & 661 & +13 & -33 & -19 & +2.9 & -6.1 & -2.8 & 3.9 & 6.1 & 13.8 \\
\hline 27 & 467 & 521 & 623 & +17 & -19 & -57 & +3.8 & -3.5 & -8.4 & 5.2 & 8.4 & 10.1 \\
\hline 28 & 433 & 497 & 623 & -17 & -43 & -57 & -3.8 & -8.0 & -8.4 & 6.7 & 8.4 & 9.3 \\
\hline 29 & 438 & 497 & 621 & -12 & -43 & -59 & -2.7 & -8.0 & -8.7 & 6.4 & 8.7 & 9.3 \\
\hline 30 & 459 & 492 & 617 & +9 & -48 & -63 & +2.0 & -8.9 & -9.3 & 6.7 & 9.3 & 8.7 \\
\hline
\end{tabular}
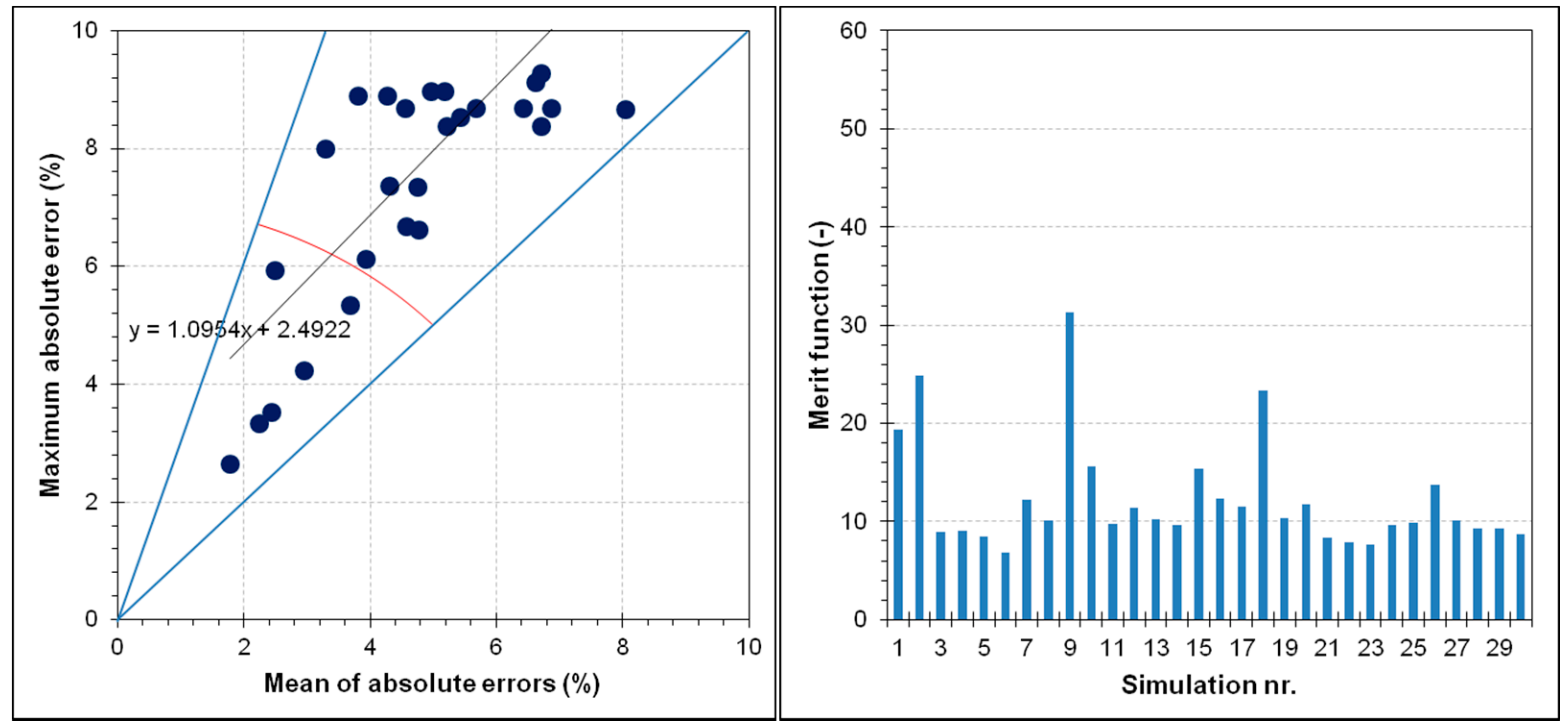

Figure 9. (left) graphical evaluation of the goodness of $n$-tuples $\left(M_{f}=14.14\right.$ at the red arc); (right) visualization of $M_{f}$ values for each of the proposed additional 30 n-tuples. 
The positioning of the points in the Cartesian plane of Figure 9 (left) shows substantial parallelism with respect to the bisector of the quadrant (the slope of the interpolation line is approximately unitary) and an average deviation of about 2.5 percentage points. Only six points are below the threshold of 14.14 of the merit function, and only four points have both coordinates below the threshold of $5 \%$, commonly considered the maximum acceptable deviation threshold for technical system simulations. More evident individuation of the best $n$-tuples can be seen in the histogram of Figure 9 on the right: the higher the bars, the higher the merit function, the closer the CFD-FVM results to the real case $\left(\mathrm{P}_{0}\right)$, the better those $n$-tuples to tune the FVM model. The higher four bars in the represented graphic correspond to $n$-tuples $1,2,9$, and 18. The best-ever combination of this set of 30 combinations of factors is the $n$-tuple number 9 , achieving a value for $M_{f}$ of 31.3 , a mean of absolute errors of $1.8 \%$ and a maximum absolute error of $2.6 \%$ (the three temperatures are: $458,535,662{ }^{\circ} \mathrm{C}$, hence, respectively, at $+8,-5$, and $-18{ }^{\circ} \mathrm{C}$ from the target values of case $\mathrm{P}_{0}$ ). Although this result would be already more than acceptable, another iteration of the optimization procedure has been performed to better illustrate the method and demonstrate that it allows even a further improvement. According to experience of the authors, two iterations of the described procedure are generally sufficient for CFD-FVM model tuning in all cases an experimenter can ever meet.

The desirability and the merit function were also correlated graphically, positioning the points for each $n$-tuple on a Cartesian plane (Figure 10). Although the figure shows a weak linear correlation, the slope of the regression line and, above all, the positioning of the points on the plane show unequivocally that high values of the merit function can reasonably be expected in correspondence of very high values of desirability.

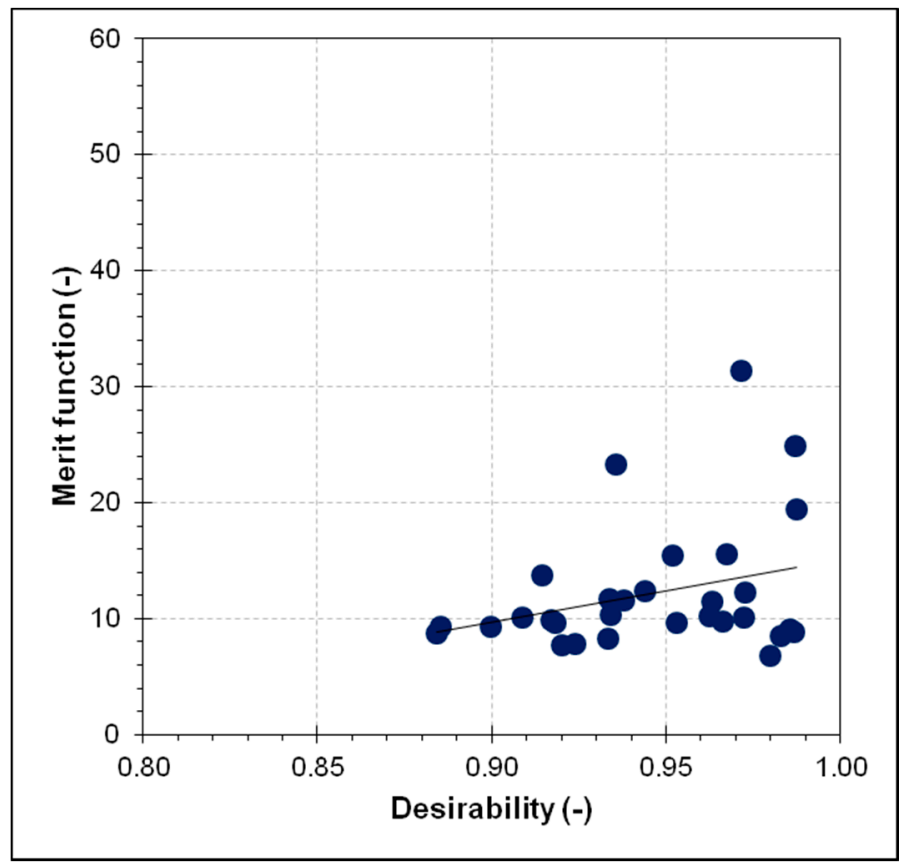

Figure 10. Graphical correlation between the desirability and the merit function.

\subsection{Second Set of RSM Models for the Exhaust Gas Temperatures}

The improvement of the predictive capacity of the RSM numerical models (and, therefore, a further closeness of the CFD-FVM model output to experimental values) occurs by increasing the calculation points of the same models, possibly in a zone of the multidimensional space of the solutions that is close to the searched optimum. This translates into using the $30 n$-tuples previously investigated as further combinations to be added to the initial 31, thus having a second dataset of 61 combinations of factors to whom the RSM method is applied a second time. Hence, another ANOVA analysis for each 
response (reported in Appendix C), performed on all the factors and based on the second dataset $(31+30=61 n$-tuples), evidenced the statistically-influencing factors for each of the three responses, which are, in this case, the same already evidenced in the previous application of RSM (Table 6): 6 for $T_{1}, 5$ for $T_{2}, 3$ for $T_{3}$. By performing again a backward elimination of the non-significant terms from the multilinear regression models based on the ANOVA results, it has been possible to arrive to three regression models that are still multilinear but have only the significant terms (Table 10).

Table 10. Multilinear regression models for the three temperatures using the second dataset of 61 cases.

\begin{tabular}{|c|c|c|}
\hline Model & $\mathbf{R}^{2}$ & Adj $R^{2}$ \\
\hline$T_{1}=+194.80036+0.46497 \cdot T+11,898.19656 \cdot \dot{m}_{e x}-2.14856 \cdot H_{h}-1.23564 \cdot H_{e x}-26.35972 \cdot e_{e x}+0.32078 \cdot C_{h}$ & 0.9798 & 0.9776 \\
\hline$T_{2}=+212.17727+0.48821 \cdot T+10,843.33590 \cdot \dot{m}_{e x}-0.31434 \cdot H_{h}-2.18245 \cdot H_{e x}-50.42908 \cdot e_{e x}$ & 0.9864 & 0.9851 \\
\hline$T_{3}=+61.55935+0.71766 \cdot T+17,518.39820 \cdot \dot{m}_{e x}-0.81363 \cdot H_{e x}$ & 0.9476 & 0.9449 \\
\hline
\end{tabular}

\subsection{Second Set of 30 Possible n-Tuples to Match the Experimental Results (2nd Dataset)}

Thanks to the internal numerical optimization routine of the RSM software, it has been possible to generate other $30 n$-tuples of values for the unknown parameters to make the FVM model match the experimental results. Even in this case, only the first 30 -tuples (i.e., with the highest value of desirability) have been selected and subsequently inquired via the FVM software. Table 11 shows the simulated $n$-tuples, together with the numerical estimates for the three temperatures, calculated with the RSM models illustrated above in Table 10. The results coming from the simulation have been collected in Table 12, together with the percentage errors (related to the experimental target values) and the aforementioned metrics, based on these errors, to evaluate each $n$-tuple. It is worth noting that also in this case there are two $n$-tuples (nr. 10,12) that correspond to a physically impossible situation; the same considerations as above apply.

The positioning of the points corresponding to the $30 n$-tuples of Table 12 in the Cartesian plane (Figure 11 left) shows a better situation than in the previous iteration under many aspects. First of all, the points are generally closer to the bisector of the quadrant, and their distance to the bisector decreases approximating to the origin (the slope of the interpolation line is greater than unitary), thus indicating a lower dispersion of the three temperature differences. Then, there are up to 15 points below the threshold of 14.14 of the merit function (i.e., under the red arc of Figure 11 left; previously, they were only 6), and 12 have both coordinates below the threshold of $5 \%$ (previously they were only 4 ). The histogram of the merit function (Figure 11 right) shows higher bars than in the previous case, indicating a closer matching of the CFD-FVM software to the reality. The four highest bars in the represented graphic correspond to $n$-tuples 3, 4, 5, and 7 (all with a value for $M_{f}$ above 30). The best-ever combination of this set of 30 combinations of factors (and also of the previous set of combinations) is the $n$-tuple number 4 , achieving a value for $M_{f}$ of 50.7 , a mean of absolute errors of $1.1 \%(-0.7$ percentage points with respect to the previous iteration) and a maximum absolute error of $1.6 \%(-1.0$ percentage points than the previous iteration); the three temperatures from the CFD-FVM model are, respectively: 453, 534, and $669{ }^{\circ} \mathrm{C}$ (i.e., $+3,-6$, and $-11^{\circ} \mathrm{C}$ with respect to case $\mathrm{P}_{0}$ ). According to these evidences, is therefore possible to state that the values of the factors associated with $n$-tuple number 4 allow having a tuned CFD-FVM model. 


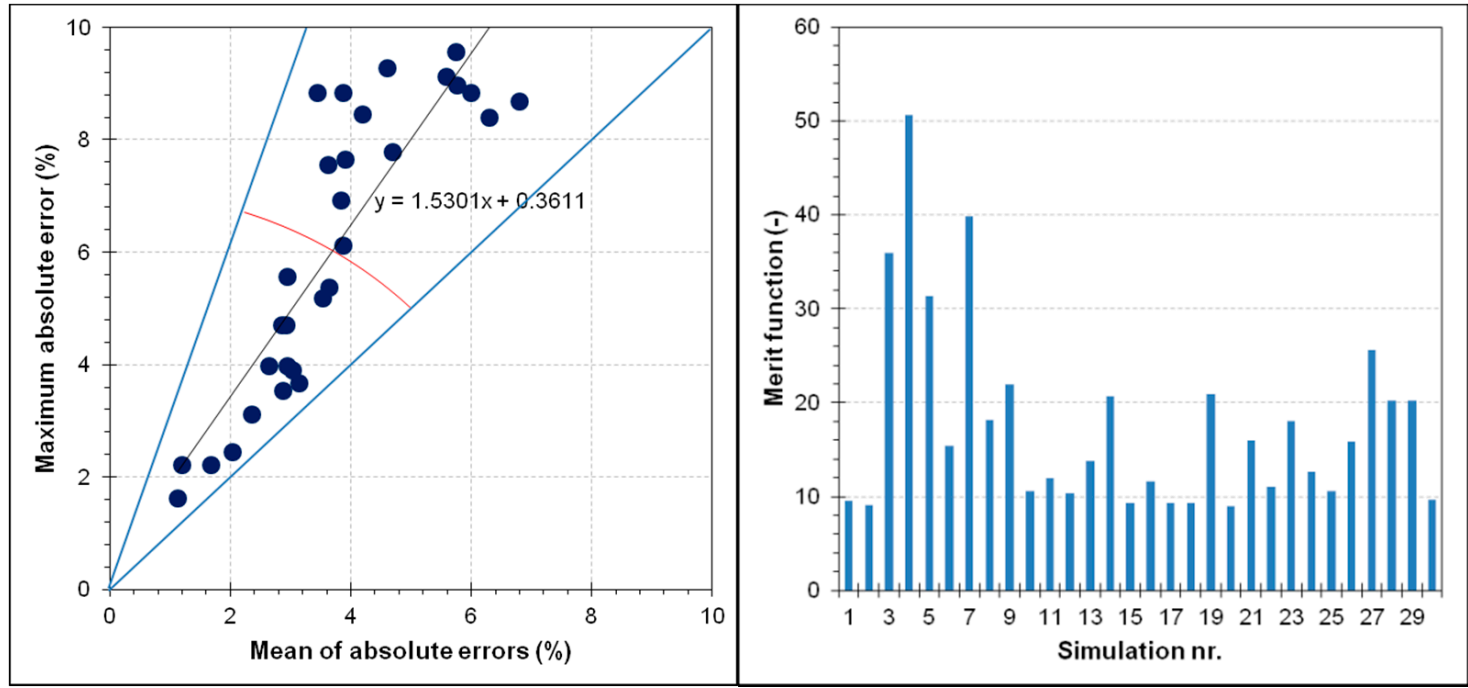

Figure 11. (left) Graphical evaluation of the goodness of $n$-tuples $\left(M_{f}=14.14\right.$ at the red arc); (right) visualization of $M_{f}$ values for each of the proposed $30 n$-tuples.

Table 11. Combinations of unknown independent parameters suggested by RSM optimization procedure, together with the outputs in terms of desirability ad foreseen temperature in the three measuring points.

\begin{tabular}{|c|c|c|c|c|c|c|c|c|c|c|c|c|}
\hline \multirow{2}{*}{ Nr. } & \multicolumn{8}{|c|}{ Factors (Unknown Independent Parameters) } & \multicolumn{4}{|c|}{$\begin{array}{l}\text { RSM Optimization } \\
\text { Procedure Outputs }\end{array}$} \\
\hline & $\begin{array}{l}T \\
\mathrm{~K} \\
\end{array}$ & $\begin{array}{c}\dot{m}_{e x} \\
\mathrm{~kg} \cdot \mathrm{s}^{-1}\end{array}$ & $\begin{array}{c}H_{h} \\
\mathrm{~W} \cdot \mathrm{m}^{-2} \mathrm{~K}^{-1}\end{array}$ & $\begin{array}{c}H_{e x} \\
\mathbf{W} \cdot \mathbf{m}^{-2} \mathbf{K}^{-1}\end{array}$ & $\begin{array}{l}e_{h} \\
-\end{array}$ & $e_{e x}$ & $\begin{array}{c}C_{h} \\
\mathrm{~W} \cdot \mathrm{m}^{-1} \cdot \mathrm{K}^{-1}\end{array}$ & $\begin{array}{c}C_{r} \\
\mathrm{~m}^{2} \cdot \mathrm{K} \cdot \mathbf{W}^{-1} \\
\end{array}$ & $\begin{array}{c}\text { Desirability } \\
-\end{array}$ & $\begin{array}{l}T_{1} \\
\mathrm{~K}\end{array}$ & $\begin{array}{l}T_{2} \\
\mathrm{~K}\end{array}$ & $\begin{array}{l}T_{3} \\
\mathrm{~K} \\
\end{array}$ \\
\hline 1 & 836 & 0.002 & 50 & 21 & 0.94 & 0.81 & 5 & 0.00074 & 0.9910 & 454 & 540 & 679 \\
\hline 2 & 831 & 0.002 & 50 & 23 & 0.36 & 0.72 & 5 & 0.00092 & 0.9900 & 452 & 537 & 674 \\
\hline 3 & 775 & 0.004 & 50 & 14 & 1.00 & 1.00 & 5 & 0.00085 & 0.9880 & 453 & 537 & 676 \\
\hline 4 & 787 & 0.004 & 50 & 24 & 0.67 & 0.67 & 5 & 0.00026 & 0.9850 & 455 & 538 & 677 \\
\hline 5 & 765 & 0.005 & 50 & 22 & 0.46 & 0.71 & 5 & 0.00120 & 0.9840 & 458 & 540 & 680 \\
\hline 6 & 825 & 0.003 & 50 & 36 & 1.00 & 0.30 & 6 & 0.00068 & 0.9830 & 456 & 538 & 677 \\
\hline 7 & 770 & 0.005 & 50 & 26 & 1.00 & 0.58 & 5 & 0.00033 & 0.9830 & 459 & 541 & 681 \\
\hline 8 & 724 & 0.007 & 50 & 21 & 0.63 & 0.71 & 5 & 0.00099 & 0.9810 & 464 & 544 & 687 \\
\hline 9 & 745 & 0.006 & 50 & 25 & 0.60 & 0.58 & 5 & 0.00114 & 0.9800 & 461 & 541 & 681 \\
\hline 10 & 679 & 0.008 & 50 & 12 & 0.72 & 0.96 & 5 & 0.00021 & 0.9790 & 460 & 540 & 679 \\
\hline 11 & 758 & 0.005 & 50 & 18 & 0.30 & 0.82 & 16 & 0.00010 & 0.9770 & 461 & 540 & 678 \\
\hline 12 & 679 & 0.008 & 50 & 11 & 0.46 & 1.00 & 8 & 0.00041 & 0.9760 & 461 & 540 & 680 \\
\hline 13 & 818 & 0.003 & 50 & 34 & 1.00 & 0.32 & 15 & 0.00120 & 0.9750 & 458 & 538 & 673 \\
\hline 14 & 748 & 0.006 & 50 & 34 & 0.36 & 0.32 & 5 & 0.00089 & 0.9740 & 458 & 536 & 676 \\
\hline 15 & 850 & 0.002 & 50 & 36 & 0.31 & 0.33 & 25 & 0.00010 & 0.9730 & 461 & 538 & 677 \\
\hline 16 & 697 & 0.007 & 50 & 16 & 0.31 & 0.85 & 20 & 0.00093 & 0.9700 & 459 & 535 & 671 \\
\hline 17 & 852 & 0.002 & 50 & 35 & 0.70 & 0.36 & 46 & 0.00119 & 0.9590 & 469 & 540 & 680 \\
\hline 18 & 852 & 0.002 & 50 & 35 & 1.00 & 0.37 & 44 & 0.00073 & 0.9590 & 468 & 539 & 680 \\
\hline 19 & 745 & 0.005 & 50 & 13 & 0.51 & 1.00 & 56 & 0.00120 & 0.9510 & 469 & 536 & 673 \\
\hline 20 & 843 & 0.002 & 50 & 34 & 1.00 & 0.37 & 59 & 0.00055 & 0.9490 & 470 & 537 & 674 \\
\hline 21 & 805 & 0.004 & 50 & 34 & 0.33 & 0.71 & 5 & 0.00118 & 0.9480 & 450 & 523 & 682 \\
\hline 22 & 742 & 0.006 & 50 & 28 & 0.30 & 0.49 & 49 & 0.00024 & 0.9480 & 472 & 538 & 676 \\
\hline 23 & 733 & 0.006 & 49 & 16 & 0.83 & 0.89 & 54 & 0.00120 & 0.9470 & 476 & 540 & 680 \\
\hline 24 & 703 & 0.007 & 50 & 13 & 0.41 & 0.96 & 67 & 0.00119 & 0.9390 & 478 & 539 & 678 \\
\hline 25 & 771 & 0.005 & 50 & 30 & 0.89 & 0.44 & 75 & 0.00010 & 0.9320 & 481 & 539 & 678 \\
\hline 26 & 814 & 0.003 & 50 & 18 & 0.93 & 0.87 & 89 & 0.00033 & 0.9320 & 485 & 543 & 684 \\
\hline 27 & 761 & 0.005 & 50 & 18 & 0.86 & 0.84 & 89 & 0.00120 & 0.9260 & 485 & 541 & 681 \\
\hline 28 & 743 & 0.007 & 48 & 31 & 1.00 & 0.86 & 5 & 0.00010 & 0.9190 & 461 & 525 & 692 \\
\hline 29 & 773 & 0.005 & 45 & 25 & 1.00 & 1.00 & 22 & 0.00117 & 0.8860 & 467 & 525 & 684 \\
\hline 30 & 801 & 0.002 & 40 & 10 & 0.99 & 1.00 & 69 & 0.00113 & 0.8840 & 489 & 540 & 663 \\
\hline
\end{tabular}


Table 12. Evaluation of each $n$-tuple with reference to the experimental target values for the temperatures.

\begin{tabular}{|c|c|c|c|c|c|c|c|c|c|c|c|c|}
\hline \multirow{2}{*}{ Nr. } & \multicolumn{3}{|c|}{$\begin{array}{c}\text { Simulation Outputs } \\
\text { (CFD-FVM) }\end{array}$} & \multicolumn{3}{|c|}{ Absolute Errors } & \multicolumn{3}{|c|}{ Percentage Errors } & \multicolumn{3}{|c|}{ Evaluation Metrics } \\
\hline & $\begin{array}{l}T_{1} \\
\mathrm{~K}\end{array}$ & $\begin{array}{c}T_{2} \\
\mathrm{~K}\end{array}$ & $\begin{array}{l}T_{3} \\
\mathrm{~K}\end{array}$ & $\begin{array}{c}\Delta T_{1} \\
\mathrm{~K}\end{array}$ & $\begin{array}{c}\Delta T_{2} \\
\mathrm{~K}\end{array}$ & $\begin{array}{c}\Delta T_{3} \\
\mathbf{K}\end{array}$ & $\begin{array}{c}\Delta T_{1} \\
\%\end{array}$ & $\begin{array}{c}\Delta T_{2} \\
\%\end{array}$ & $\begin{array}{c}\Delta T_{3} \\
\%\end{array}$ & $\begin{array}{c}\text { Mean abs. Err. } \\
\%\end{array}$ & $\begin{array}{c}\text { Max abs. Err. } \\
\%\end{array}$ & $\begin{array}{c}M_{f} \\
-\end{array}$ \\
\hline 1 & 421 & 518 & 623 & -29 & -22 & -57 & -6.4 & -4.1 & -8.4 & 6.3 & 8.4 & 9.5 \\
\hline 2 & 418 & 515 & 621 & -32 & -25 & -59 & -7.1 & -4.6 & -8.7 & 6.8 & 8.7 & 9.1 \\
\hline 3 & 440 & 536 & 666 & -10 & -4 & -14 & -2.2 & -0.7 & -2.1 & 1.7 & 2.2 & 35.9 \\
\hline 4 & 453 & 534 & 669 & +3 & -6 & -11 & +0.7 & -1.1 & -1.6 & 1.1 & 1.6 & 50.7 \\
\hline 5 & 439 & 532 & 665 & -11 & -8 & -15 & -2.4 & -1.5 & -2.2 & 2.0 & 2.4 & 31.4 \\
\hline 6 & 433 & 511 & 668 & -17 & -29 & -12 & -3.8 & -5.4 & -1.8 & 3.6 & 5.4 & 15.4 \\
\hline 7 & 453 & 536 & 665 & +3 & -4 & -15 & +0.7 & -0.7 & -2.2 & 1.2 & 2.2 & 39.8 \\
\hline 8 & 440 & 531 & 648 & -10 & -9 & -32 & -2.2 & -1.7 & -4.7 & 2.9 & 4.7 & 18.2 \\
\hline 9 & 437 & 528 & 656 & -13 & -12 & -24 & -2.9 & -2.2 & -3.5 & 2.9 & 3.5 & 22.0 \\
\hline 10 & 451 & 533 & 620 & +1 & -7 & -60 & +0.2 & -1.3 & -8.8 & 3.4 & 8.8 & 10.6 \\
\hline 11 & 484 & 542 & 660 & +34 & +2 & -20 & +7.6 & +0.4 & -2.9 & 3.6 & 7.6 & 11.9 \\
\hline 12 & 456 & 532 & 620 & +6 & -8 & -60 & +1.3 & -1.5 & -8.8 & 3.9 & 8.8 & 10.4 \\
\hline 13 & 435 & 507 & 665 & -15 & -33 & -15 & -3.3 & -6.1 & -2.2 & 3.9 & 6.1 & 13.8 \\
\hline 14 & 440 & 521 & 655 & -10 & -19 & -25 & -2.2 & -3.5 & -3.7 & 3.1 & 3.7 & 20.7 \\
\hline 15 & 456 & 506 & 618 & +6 & -34 & -62 & +1.3 & -6.3 & -9.1 & 5.6 & 9.1 & 9.4 \\
\hline 16 & 455 & 524 & 628 & +5 & -16 & -52 & +1.1 & -3.0 & -7.6 & 3.9 & 7.6 & 11.6 \\
\hline 17 & 442 & 500 & 620 & -8 & -40 & -60 & -1.8 & -7.4 & -8.8 & 6.0 & 8.8 & 9.4 \\
\hline 18 & 445 & 501 & 619 & -5 & -39 & -61 & -1.1 & -7.2 & -9.0 & 5.8 & 9.0 & 9.4 \\
\hline 19 & 462 & 533 & 653 & +12 & -7 & -27 & +2.7 & -1.3 & -4.0 & 2.6 & 4.0 & 21.0 \\
\hline 20 & 448 & 501 & 615 & -2 & -39 & -65 & -0.4 & -7.2 & -9.6 & 5.7 & 9.6 & 9.0 \\
\hline 21 & 431 & 512 & 672 & -19 & -28 & -8 & -4.2 & -5.2 & -1.2 & 3.5 & 5.2 & 15.9 \\
\hline 22 & 485 & 529 & 651 & +35 & -11 & -29 & +7.8 & -2.0 & -4.3 & 4.7 & 7.8 & 11.0 \\
\hline 23 & 460 & 530 & 648 & +10 & -10 & -32 & +2.2 & -1.9 & -4.7 & 2.9 & 4.7 & 18.0 \\
\hline 24 & 460 & 527 & 633 & +10 & -13 & -47 & +2.2 & -2.4 & -6.9 & 3.8 & 6.9 & 12.6 \\
\hline 25 & 488 & 531 & 663 & +38 & -9 & -17 & +8.4 & -1.7 & -2.5 & 4.2 & 8.4 & 10.6 \\
\hline 26 & 475 & 531 & 669 & +25 & -9 & -11 & +5.6 & -1.7 & -1.6 & 2.9 & 5.6 & 15.9 \\
\hline 27 & 464 & 533 & 662 & +14 & -7 & -18 & +3.1 & -1.3 & -2.6 & 2.4 & 3.1 & 25.6 \\
\hline 28 & 456 & 521 & 653 & +6 & -19 & -27 & +1.3 & -3.5 & -4.0 & 2.9 & 4.0 & 20.2 \\
\hline 29 & 461 & 519 & 661 & +11 & -21 & -19 & +2.4 & -3.9 & -2.8 & 3.0 & 3.9 & 20.3 \\
\hline 30 & 458 & 525 & 617 & +8 & -15 & -63 & +1.8 & -2.8 & -9.3 & 4.6 & 9.3 & 9.7 \\
\hline
\end{tabular}

\subsection{Values of Unknown Parameters and Relation with the Engine Torque (Step 2.2)}

The above-described iterative procedure of CFD-FVM model tuning allows to find the values of a set of unknown parameters used in the CFD-FVM simulation, but that is also interesting from an experimental point of view (Table 13).

Table 13. Best combination of unknown independent parameters to make the CFD-FVM model output coincident with experimental results.

\begin{tabular}{|c|c|c|c|c|c|c|c|c|}
\hline \multirow[b]{2}{*}{ Nr. } & \multicolumn{8}{|c|}{ Factors (Unknown Independent Parameters) } \\
\hline & $\begin{array}{l}T \\
\mathrm{~K} \\
\end{array}$ & $\begin{array}{c}\dot{m}_{e x} \\
\mathrm{~kg} \cdot \mathrm{s}^{-1}\end{array}$ & $\begin{array}{c}H_{h} \\
\mathbf{W} \cdot \mathbf{m}^{-2} K^{-1}\end{array}$ & $\begin{array}{c}H_{e x} \\
\mathrm{~W} \cdot \mathrm{m}^{-2} \mathrm{~K}^{-1}\end{array}$ & $e_{h}$ & $\begin{array}{c}e_{e x} \\
-\end{array}$ & $\begin{array}{c}C_{h} \\
\mathbf{W} \cdot \mathbf{m}^{-1} \cdot \mathrm{K}^{-1}\end{array}$ & $\begin{array}{c}C_{r} \\
\mathrm{~m}^{2} \cdot \mathrm{K} \cdot \mathrm{W}^{-1}\end{array}$ \\
\hline 4 & 787 & 0.004 & 50 & 24 & 0.67 & 0.67 & 5 & 0.00026 \\
\hline
\end{tabular}

The first three factors are directly related to the inquired engine operative condition and, in particular, two of them to the exhaust gas stream. They are, therefore, very important for the overall aim of this study, i.e., the indirect prediction of the torque delivered by the engine at the different engine speeds:

- The temperature of the exhaust gas at the inlet of the exhaust pipe $T$, i.e., at the outlet of the exhaust valve in the motor head, related to the torque (see the following Section); 
- The mass flow rate of the exhaust gas flowing along the exhaust pipeline $\dot{m}_{e x}$, related to the engine speed and to the governor action;

- The convective coefficient of the motor head $H_{h}$, whose cooling is related to the fan speed (integrated to the flywheel in the used engine), hence to the engine speed.

The other five parameters depend on external/environmental conditions (the convective coefficient of the motor head) or by the material $\left(C_{r}\right.$ and $\left.C_{h}\right)$ and the surface finishing $\left(e_{e x}\right.$ and $\left.e_{h}\right)$ of the components of the assembly.

This means that having other experimental measurements of the temperature at the same three positions but at different engine speeds and loads (i.e., in an operative point different from $\mathrm{P}_{0}$ ), there are two possible ways to proceed to obtain again the values of the three above-listed parameters related to the inquired engine operative condition (in particular, the temperature of the exhaust gas at the inlet of the exhaust pipe $T$ ):

1. To retrace, for each experimental case (different from $\mathrm{P}_{0}$ ), the whole tuning procedure of the FVM software illustrated, thus obtaining again the values of all the unknown parameters (and, among these ones, also the first three parameters of interest);

2. To carry out a fast recalculation procedure of the first three parameters, based on the RSM numerical models, illustrated in the following paragraph (referred to as: 2nd sub-procedure about fast recalculating the CFD-FVM model tuning parameters).

As will be shown, the second approach to the problem is much more efficient (i.e., faster and less resource-intensive) than the first one, and, therefore, it is preferable. The following steps are taken:

1. The mass flow rate, in this case, is calculated from the speed of rotation through a simple linear correlation from the value found for case $\mathrm{P}_{0}$, as it is minimally influenced by the mass flow rate of the fuel and assuming a constant volumetric efficiency (simplifying hypothesis valid for speeds of rotation of the new cases close to those of the initial tuning for the FVM model);

2. A system of two equations (i.e., two of the three RSM models for $T_{1}, T_{2}, T_{3}$ ) for the two unknown quantities ( $T$ and $H_{h}$ ) is set up by fixing two of the three experimentally measured temperatures, then solving the system for the third value; since there are three temperatures, the previous step is repeated three times, changing the pair of temperatures to be matched each time;

$$
\begin{aligned}
& \left\{\begin{array} { l } 
{ T _ { 1 } = f _ { 1 } ( T ; H _ { h } ) = T _ { 1 , \operatorname { e x p } } } \\
{ T _ { 2 } = f _ { 2 } ( T ; H _ { h } ) = T _ { 2 , \operatorname { e x p } } }
\end{array} \Rightarrow \left\{\begin{array}{c}
T * \\
H_{h} *
\end{array} \Rightarrow T_{3}=f_{3}\left(T * ; H_{h} *\right)\right.\right. \\
& \left\{\begin{array} { l } 
{ T _ { 2 } = f _ { 2 } ( T ; H _ { h } ) = T _ { 2 , \operatorname { e x p } } } \\
{ T _ { 3 } = f _ { 3 } ( T ; H _ { h } ) = T _ { 3 , \operatorname { e x p } } }
\end{array} \Rightarrow \left\{\begin{array}{c}
T * \\
H_{h} *
\end{array} \Rightarrow T_{1}=f_{1}\left(T * ; H_{h} *\right)\right.\right. \\
& \left\{\begin{array} { l } 
{ T _ { 1 } = f _ { 1 } ( T ; H _ { h } ) = T _ { 1 , \operatorname { e x p } } } \\
{ T _ { 3 } = f _ { 3 } ( T ; H _ { h } ) = T _ { 3 , \operatorname { e x p } } }
\end{array} \Rightarrow \left\{\begin{array}{c}
T * \\
H_{h} *
\end{array} \Rightarrow T_{2}=f_{2}\left(T * ; H_{h} *\right)\right.\right.
\end{aligned}
$$

3. The parameters $T$ and $\dot{m}_{e x}$ that will be chosen for each case will then be the arithmetic averages of the values obtained in the previous step (i.e., $T$ and $\dot{m}_{e x}$ will be calculated as the average of the three values obtained in the previous step).

The results of the sub-procedure listed above are shown in Table 14, whereas Figure 12 shows the relative positioning of the parameters used for the matching on a two-axis diagram.

By observing the results, in particular the average and the maximum of absolute errors, we can state that:

- A parameter-matching procedure based only on $T_{2}$ and $T_{3}$ (i.e., on the temperatures at the clamp and the thermowell) gives the worst results (average of absolute errors: $\leq 3.5 \%$; the maximum of absolute errors: $\leq 10.4 \%$ ); this fact evidences a substantial homogeneity of the measures at those two measuring points and a clear difference in the behavior of temperature taken at the grommet; if the problem is inquired by setting the matching point at the clamp and the thermowell, there is an underestimation of temperature at the grommet $\left(T_{1}\right)$; 
- For the same reason, if this parameter-matching procedure involves the temperature at the grommet $\left(T_{1}\right)$ and one of the temperatures measured at the clamp and at the thermowell (i.e., $T_{2}$ or $T_{3}$ ), the results will be better; this can be clearly seen by looking at the results and at the average and the maximum of absolute errors, all largely within the threshold $5 \%$ (average of absolute errors: $\leq 0.6 \%$; the maximum of absolute errors: $\leq 1.8 \%$;

- $\quad$ By using for $T$ and $\dot{m}_{e x}$ in each of the three additional cases the average values resulting from the parameter-matching procedure based respectively on $T_{1}$ and $T_{2}$, on $T_{2}$ and $T_{3}, T_{1}$ and $T_{3}$, the results (in terms of forecasted temperatures $T_{1}, T_{2}, T_{3}$ ) are very close to the experimental values, and the average and the maximum of absolute errors are all lower than $5 \%$ (average of absolute errors: $\leq 1.5 \%$; the maximum of absolute errors: $\leq 3.5 \%$ ).

Table 14. Steps of the parameter-recalculation procedure for the experimental points $P_{1}, P_{2}, P_{3}$ using the results obtained from the RSM model.

\begin{tabular}{|c|c|c|c|c|c|c|c|c|c|c|c|c|c|c|c|}
\hline \multirow{2}{*}{ Descript. } & & \multicolumn{3}{|c|}{ Parameters } & \multicolumn{3}{|c|}{ Experim. } & \multicolumn{3}{|c|}{ RSM } & \multicolumn{3}{|c|}{ Relative Err. } & \multirow{2}{*}{$\begin{array}{l}\text { Ave } \\
\%\end{array}$} & \multirow{2}{*}{$\begin{array}{l}\text { Max } \\
\%\end{array}$} \\
\hline & & $\begin{array}{l}T \\
\mathrm{~K} \\
\end{array}$ & $\begin{array}{c}\dot{m}_{e x} \\
\mathrm{~kg} \cdot \mathrm{s}^{-1}\end{array}$ & $\begin{array}{c}H_{h} \\
\mathbf{W} \cdot \mathbf{m}^{-2} \mathrm{~K}^{-1}\end{array}$ & $\begin{array}{l}T_{1} \\
\mathrm{~K}\end{array}$ & $\begin{array}{l}T_{2} \\
\mathrm{~K}\end{array}$ & $\begin{array}{l}T_{3} \\
\mathbf{K}\end{array}$ & $\begin{array}{l}T_{1} \\
\mathrm{~K}\end{array}$ & $\begin{array}{l}T_{2} \\
\mathrm{~K}\end{array}$ & $\begin{array}{l}T_{3} \\
\mathrm{~K}\end{array}$ & $\begin{array}{l}T_{1} \\
\%\end{array}$ & $\begin{array}{l}T_{2} \\
\%\end{array}$ & $\begin{array}{l}T_{3} \\
\%\end{array}$ & & \\
\hline Ref. case & $\mathrm{P}_{0}$ & 787 & 0.0040 & 50.0 & 450 & 540 & 680 & 455 & 538 & 677 & +1.2 & -0.4 & -0.5 & 0.7 & 1.2 \\
\hline \multirow{3}{*}{ Match on $T_{1}, T_{2}$} & $P_{1}$ & 784 & 0.0033 & 48.7 & 448 & 529 & 673 & 448 & 529 & 662 & 0.0 & 0.0 & -1.6 & 0.5 & 1.6 \\
\hline & $\mathrm{P}_{2}$ & 710 & 0.0040 & 41.3 & 438 & 503 & 633 & 438 & 503 & 622 & 0.0 & 0.0 & -1.8 & 0.6 & 1.8 \\
\hline & $\mathrm{P}_{3}$ & 658 & 0.0040 & 33.8 & 430 & 480 & 591 & 430 & 480 & 584 & 0.0 & 0.0 & -1.1 & 0.4 & 1.1 \\
\hline \multirow{3}{*}{ Match on $T_{2}, T_{3}$} & $\mathrm{P}_{1}$ & 799 & 0 & 72.2 & 448 & 529 & 673 & 405 & 529 & 673 & -9.7 & 0.0 & 0.0 & 3.2 & 9.7 \\
\hline & $\mathrm{P}_{2}$ & 726 & 0.0040 & 66.0 & 438 & 503 & 633 & 392 & 503 & 633 & -10.4 & 0.0 & 0.0 & 3.5 & 10.4 \\
\hline & $\mathrm{P}_{3}$ & 667 & 0.0040 & 48.2 & 430 & 480 & 591 & 403 & 480 & 591 & -6.2 & 0.0 & 0.0 & 2.1 & 6.2 \\
\hline \multirow{3}{*}{ Match on $T_{1}, T_{3}$} & $\mathrm{P}_{1}$ & 799 & & 52.0 & 448 & 529 & 673 & 448 & 535 & 67 & 0.0 & +1.2 & 0.0 & 0.4 & 1.2 \\
\hline & $\mathrm{P}_{2}$ & 726 & 0.0040 & 44.8 & 438 & 503 & 633 & 438 & 510 & 633 & 0.0 & +1.3 & 0.0 & 0.4 & 1.3 \\
\hline & $\mathrm{P}_{3}$ & 667 & 0.0040 & 35.8 & 430 & 480 & 591 & 430 & 484 & 591 & 0.0 & +0.8 & 0.0 & 0.3 & 0.8 \\
\hline \multirow{3}{*}{$\begin{array}{c}\text { Average } \\
\text { values from } \\
\text { previous cases }\end{array}$} & $\mathrm{P}_{1}$ & 794 & 0.0033 & 58.0 & 448 & 529 & 673 & 434 & 531 & 669 & -3.2 & +0.4 & -0.5 & 1.4 & 3.2 \\
\hline & $\mathrm{P}_{2}$ & 721 & 0.0040 & 51.0 & 438 & 503 & 633 & 423 & 505 & 629 & -3.5 & +0.4 & -0.6 & 1.5 & 3.5 \\
\hline & $\mathrm{P}_{3}$ & 664 & 0.0040 & 39.0 & 430 & 480 & 591 & 421 & 481 & 589 & -2.1 & +0.3 & -0.4 & 0.9 & 2.1 \\
\hline
\end{tabular}

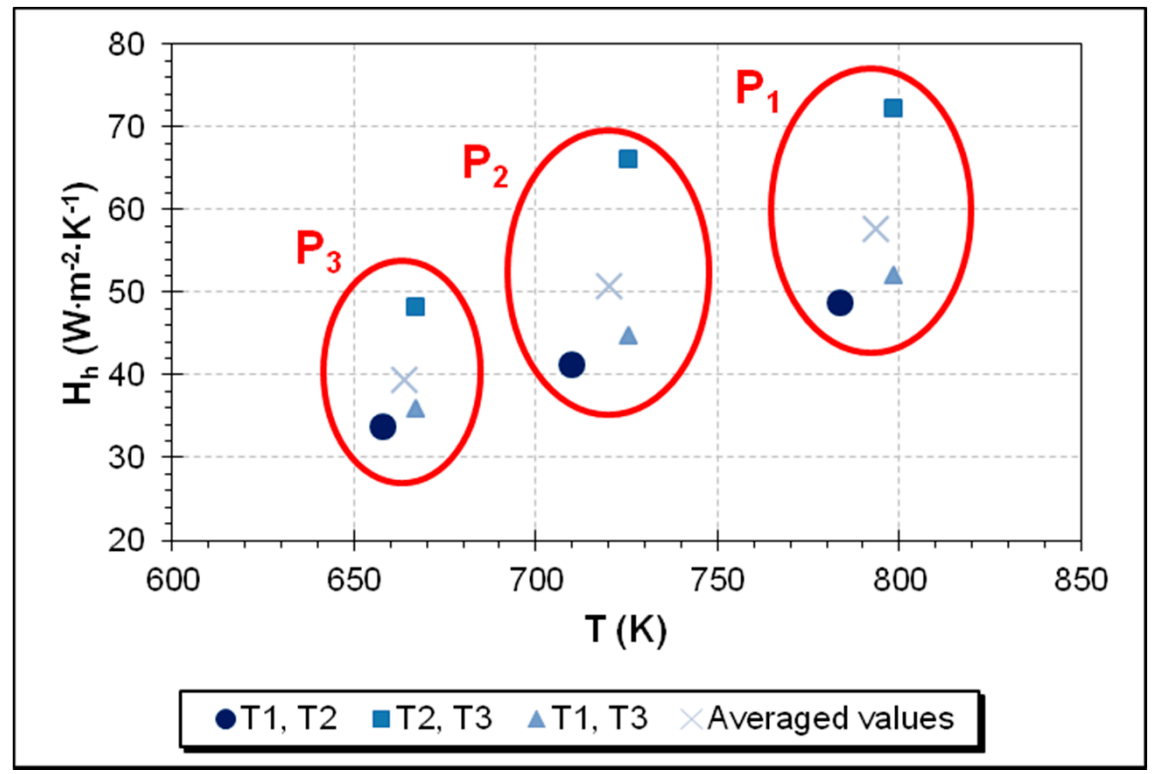

Figure 12. Relative positioning of parameters values to match the experimental temperatures in the three indicated cases $\left(\mathrm{P}_{1}, \mathrm{P}_{2}, \mathrm{P}_{3}\right)$. 


\subsection{Relation of Temperatures in the Exhaust Gas Line with the Engine Torque (Step 3)}

Thanks to the experimental cases reported in this article $\left(\mathrm{P}_{0}, \mathrm{P}_{1}, \mathrm{P}_{2}\right.$, and $\mathrm{P}_{3}$ in Table 3$)$, of which the exhaust gas temperature at the exhaust valve (i.e., at the exhaust pipe inlet) has been calculated, it is possible to illustrate a third sub-procedure useful to foresee the torque delivered by the engine (namely: third sub-procedure about creating the torque prediction model; Figure 13). In this regard, with the aim of illustrating and verifying the procedure, the four experimental cases will be divided into two sets:

- The first set, including $\mathrm{P}_{0}$ and $\mathrm{P}_{3}$, will be used to create a simple (linear) model of the torque as a function of the temperature $T$ (set of torque model creation points);

- The second set, including $P_{1}$ and $P_{2}$, will be used to verify the goodness of the predictive model for the torque (set of verification points).

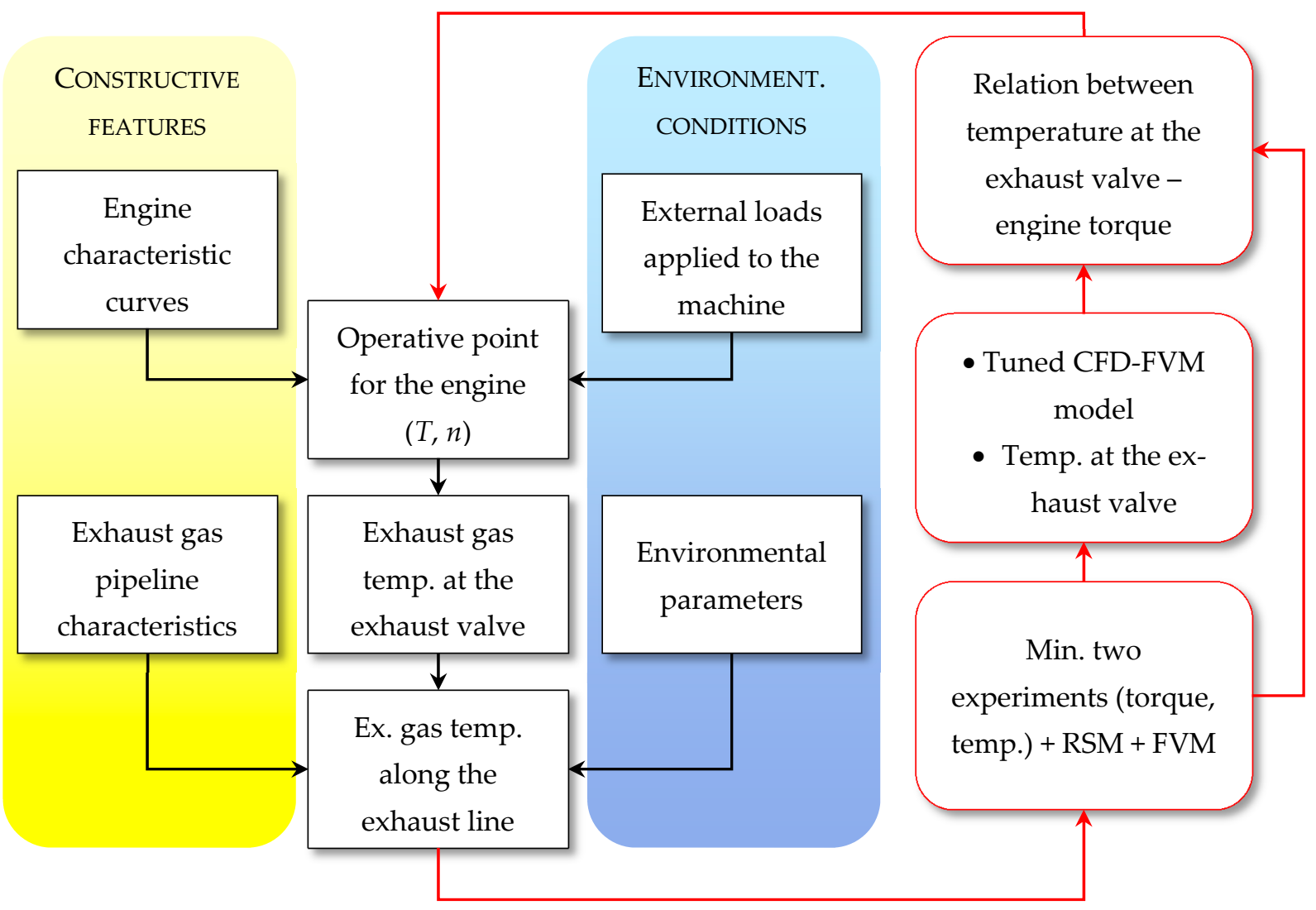

Figure 13. Procedure used to set up a torque prediction model based on the exhaust gas temperature at the exhaust valve, obtained by tuning of a CFD-FVM software model aided by the RSM.

It is worth noting that two is the minimum number of experimental cases needed to build such a predictive model; it is possible to use more than two cases so that the final predictive capabilities can be further improved. Similar to other studies articulated in experimental and numerical phases, the best number of cases to be used to set up the torque prediction model should be set as a trade-off between the costs, due to an addition of experimental activities, and the desired predictive capability of the model. When planning the operative conditions to be experimentally inquired and, hence, the experimental cases that will be used to be part of the model, the only recommendation is to have them as distant as possible in terms of torque values. By doing so, the model that will be set up, will be used only to interpolate other values and not to extrapolate them, so as it will be more reliable in its results.

Using the EGT value for the point $\mathrm{P}_{0}$, deriving from the model tuning procedure (1st sub-procedure), and the EGT value for the point $\mathrm{P}_{1}$, deriving instead from the fast 
recalculation procedure (2nd sub-procedure), it is now possible to calculate a model to predict the torque as a linear function the EGT (3rd sub-procedure):

$$
\begin{aligned}
& M=0.0225 \cdot T-9.5982 \\
& T=f\left(T_{1}, T_{2}, T_{3}, \text { other CFD - FVM parameters }\right)
\end{aligned}
$$

To have a comparison and evaluate the whole procedure, it is possible to use the data related to the experimental cases $\mathrm{P}_{0}$ and $\mathrm{P}_{3}$ to calculate also the three numerical models allowing the prediction of the torque, respectively, as a linear function of directly the three experimental temperatures $T_{1}, T_{2}, T_{3}$. The models are reported hereinafter:

$$
\begin{aligned}
& M=0.1380 \cdot T_{1}-54.0100 \\
& M=0.0460 \cdot T_{2}-16.7500 \\
& M=0.0310 \cdot T_{3}-12.9976
\end{aligned}
$$

Each of these four equations allows estimating the engine torque in correspondence with the two experimental cases $P_{1}$ and $P_{2}$. Observing the mean values for the torque reported in Table 15, it is possible to observe that the model based on $T$ is more precise than the other models, based instead on the three experimental temperatures $T_{1}, T_{2}, T_{3}$. Indeed, the model based on $T$ has a maximum absolute relative error of $2.9 \%$ of the foreseen mean values with respect to the mean experimental values, compared to: $5.2 \%$ for model based on $T_{1}$ (TC1: grommet), $6.9 \%$ for model based on $T_{2}$ (TC2: clamp), and $3.4 \%$ for model based on $T_{3}$ (TC3: thermowell). By keeping into account also the confidence intervals, it is possible to observe that there is a very high superimposition of torque prediction intervals based on $T$ with the experimental values in terms of intervals' width and vertical placement. Rather, the predictions based only on a single TC value can have a very wide uncertainty range (see TC1) or a very different vertical placement of the prediction interval, so the torque forecasts can be considered substantially different from the experimental values

\begin{tabular}{|c|c|c|c|c|c|c|c|c|c|}
\hline & \multirow{2}{*}{$\begin{array}{c}\text { Exp. } \\
M \\
\text { Nm }\end{array}$} & \multicolumn{4}{|c|}{ Torque Forecasts Model } & \multicolumn{4}{|c|}{$\begin{array}{l}\text { Forecast Errors on } \\
\text { Torque Predictions }\end{array}$} \\
\hline & & $\begin{array}{l}\text { on } T \\
\mathrm{Nm}\end{array}$ & $\begin{array}{c}\text { on } T_{1} \\
\mathrm{Nm}\end{array}$ & $\begin{array}{c}\text { on } T_{2} \\
\mathrm{Nm}\end{array}$ & $\begin{array}{c}\text { on } T_{3} \\
\mathrm{Nm}\end{array}$ & $\begin{array}{c}\text { on } T \\
\%\end{array}$ & $\begin{array}{c}\text { on } T_{1} \\
\%\end{array}$ & $\begin{array}{c}\text { on } T_{2} \\
\%\end{array}$ & $\begin{array}{c}\text { on } T_{3} \\
\%\end{array}$ \\
\hline$P_{1}$ & $8.15( \pm 0.31)$ & $8.24( \pm 0.37)$ & $7.81( \pm 1.26)$ & $7.58( \pm 0.42)$ & $7.87( \pm 0.39)$ & +1.1 & -4.1 & -6.9 & -3.4 \\
\hline $\mathrm{P}_{2}$ & $6.79( \pm 0.25)$ & $6.60( \pm 0.37)$ & $6.43( \pm 1.25)$ & $6.39( \pm 0.42)$ & $6.63( \pm 0.38)$ & -2.9 & -5.2 & -5.9 & -2.3 \\
\hline
\end{tabular}
(see TC2). TC3 shows a slightly better forecast than TC1 and TC2, however not as good as the forecasts based on $T$, which instead manage to be very precise at high engine loads.

Table 15. Torque values as resulting from the use of the linear torque-prediction models, accompanied by expanded uncertainty values ( $95 \%$ confidence).

\section{Conclusions}

This study proposes a general procedure whose main purpose is to improve the accuracy of the indirect prediction of the torque delivered by a compression-ignition engine for agricultural purposes from a series of (three) temperatures measured along the exhaust pipe through three thermocouples freely placed on it. This procedure tries to overcome all the problems of metrological nature related to the positioning of temperature sensors positioned along the exhaust line and, therefore, to their physical distance from the point of heat generation, i.e., the combustion chamber. The proposed procedure uses the detected temperature values to tune a CFD-FVM model of the exhaust line with the aim of calculating the temperature of the exhaust gases closer to the engine head, hence more significant to infer the mechanical performance.

More in detail, the CFD-FVM model has been properly tuned on a first single operative point of the engine $\left(\mathrm{P}_{0}\right)$ with the help of the RSM, applied iteratively to generate a multilinear predictive model and new $n$-tuple of parameters having an estimated output 
(temperatures $T_{1}, T_{2}, T_{3}$ ) closer and closer to the experimental evidence (1st sub-procedure about CFD-FVM model tuning). Thanks to a merit function defined for this purpose, it has been possible to individuate the best values of a set of physical parameters related to heat transfer in the three-dimensional domain so as to have a CFD-FVM model fully aligned with the experimental results. In particular, this tuned CFD-FVM model has both the average and the maximum value of the absolute percentage errors fully below the acceptability threshold of 5\% (typical for simulations), precisely reaching $1.1 \%$ and 1.6\%, respectively, for the average and the maximum of the absolute values of relative percentage errors. Among the physical parameters object of the model tuning algorithm, there is also the EGT evaluated at the inlet of the exhaust pipe, i.e., at the exit of the exhaust valve in the engine head, which is the real aim of the use of the CFD-FVM software. This temperature is the one that, more than any other temperature measured along the exhaust line, allows an accurate valuation of the torque delivered by the engine, as demonstrated in the second part of the article using a simple linear model. As the setup of such a linear model requires at least another value for the exhaust gas temperature at the exit of the exhaust valve, the present study proposes another algorithm (2nd sub-procedure about fast recalculating the CFD-FVM model tuning parameters) to calculate the exhaust gas temperature in another operative point of the engine (here: $\mathrm{P}_{3}$ ) on the basis of the first tuned CFD-FVM model, without repeating the previously-illustrated tuning procedure. In addition, in this case, this sub-procedure demonstrated its effectiveness: the average and maximum of absolute values of relative errors on the temperatures are all lower than $5 \%$ (average: $\leq 1.5 \%$; maximum: $\leq 3.5 \%$ ).

Finally, thanks to the use of the CFD-FVM model, which addresses all non-linearities in the system (especially in the correlation of the exhaust gas temperature with the temperatures measured in other three points of the exhaust line) and the dependence of them by the engine speed, it was possible to set up a simple (linear) model to estimate the torque based on only the exhaust gas temperature in the operative points $\mathrm{P}_{0}$ and $\mathrm{P}_{3}$ ( $3 \mathrm{rd}$ sub-procedure about creating the torque prediction model). The torque estimations based on this temperature have a maximum absolute relative error of $2.9 \%$ and expanded uncertainty intervals very close to what determined experimentally at the engine test stand, as emerges from a numerical comparison with the experimental values of the torque in other two operative points $P_{1}$ and $P_{2}$, used as verification points. The obtained value is more than acceptable for a proficient use of all the illustrated procedure in possible future applications where there is the need to indirectly estimate and monitor the engine performance of compression-ignition engines, e.g., in heavy-duty applications (agricultural machinery, cogeneration units) with no electronics to interface. Indeed, after repeating the illustrated procedure on a model of vehicle to be monitored, the simple algebraic equations constituting the indirect torque-estimating model can be stored in a controller and used in all the vehicles of the same model, hence having the same exhaust lines, and with the temperature probes are positioned in the same points. In all other vehicles, experimenters have to repeat the illustrated procedure taking care to accurately model the exhaust line via CFD-FVM software, placing in the model the thermocouples in the same position where they are effectively, as did in the illustrated case study.

This study can be framed in a wider research project carried on by the authors, aimed at the development of an independent low-cost monitoring system able to retrofit and collect data from ICE-powered agricultural machines not originally equipped with an engine-management/diagnostic system. When ready, such a monitoring system will be used to develop a predictive-maintenance logic able to keep the machines performance, the fuel consumptions and the engine overall efficiency under control and always at a level adequate to keep as low as possible the environmental impact of these machines. 
Author Contributions: The authors contributed equally to each part of this work. All authors have read and agreed to the published version of the manuscript.

Funding: This work was supported by the Open Access Publishing Fund of the Free University of Bozen/Bolzano. In addition, this research was developed within the "BIO-TRACT-EFFICIENCY" ("Experimental investigation on the efficiency of agricultural machines powered with different fuels") internal research project, grant number TN200F.

Institutional Review Board Statement: Not applicable.

Informed Consent Statement: Not applicable.

Data Availability Statement: Not applicable.

Conflicts of Interest: The authors declare no conflict of interest. The funders had no role in the design of the study; in the collection, analyses, or interpretation of data; in the writing of the manuscript; or in the decision to publish the results.

\section{Appendix A. Remarks on the RSM-Based Optimization}

The numerical optimization of multiple responses, proposed by the used statistical software, is based on the maximization of a (global) "desirability" function $(D)$ [75]. This desirability function was used by the RSM software to identify the $30 n$-tuples of factors that, if set in the CFD-FVM program, would most likely result in an output close to the experimental situation. The desirability function is an objective function that keeps into account the reaching of multiple goals together, each one formulated through a "utility" function $d_{i}$, i.e., a dimensionless individual desirability, in this case having a value included in the variability range $\left[y_{\min , i} ; y_{\max , i}\right]$ and depending by the distance of each response $x_{i}$ from its target value $x_{t, i}[76]$. More in detail, $D$ ranges from zero to one (at the simultaneous matching of all goals $d_{i}$ ) and it is formulated as the geometric mean of all these utility functions, as follows:

$$
\begin{aligned}
& d_{i}=\left\{\begin{array}{l}
1 \text { for } y_{i}=y_{t, i} \\
\frac{y_{t, i}-y_{i}}{y_{t, i}-y_{\min , i}} \text { for }\left(y_{\min , i} \leq y_{i} \leq y_{t, i}\right) \\
\frac{y_{i}-y_{t, i}}{y_{\max , i}-y_{t, i}} \text { for }\left(y_{t, i} \leq y_{i} \leq y_{\max , i}\right) \\
0 \text { for }\left(y_{i}<y_{\min , i} \vee y_{i}>y_{\max , i}\right)
\end{array}\right. \\
& D=\left(\prod_{i=1}^{n} d_{i}^{r_{i}}\right)^{\frac{1}{\sum_{r_{i}}} \text { (if all weights are equal) }} \stackrel{\prod_{i=1}^{n} d_{i}}{=}
\end{aligned}
$$

where:

- $\quad n$ is the number of simultaneously-optimized responses, i.e., for which a goal is formulated; in the present case $n=3$ because a specific $n$-tuple is evaluated by the distance of its predicted outputs of $T_{1}, T_{2}, T_{3}$ from the target values corresponding to the operative point $\mathrm{P}_{0}$;

- $d_{i}$ is the "desirable range" for a single generic response $i$, i.e., a metric related to the closeness of an output from its target value; the desirable ranges are all from zero to one (i.e., from least to most desirable value, respectively);

- $\quad r$ is a weight accounting for the importance of that factor over the others (in the present case, all weights were set at the same value, meaning that no temperature of the three is more important than the others to be matched).

If any of the responses $y_{i}$ falls outside their desirability range, the overall function becomes zero. For a simultaneous optimization, each response must range within an assigned low and high variation value (not necessarily equally distant from the target value), and the individual desirability is formulated in this case as "being equal to a target value". If the weight is 1 for a specific response, the desirability values are linearly increasing from 0 (response lower or equal to the minimum value, or higher or equal to the maximum value for that response) to 1 (response perfectly equal to the target); see Figure A1. Finding an initial feasible region where all responses are within their ranges can 
be difficult. So the RSM program used a penalty function in a downhill simplex (NelderMead) multidimensional pattern search [77] that converges at either a stationary point or a design space boundary. Some example of applications can be found in $[78,79]$.

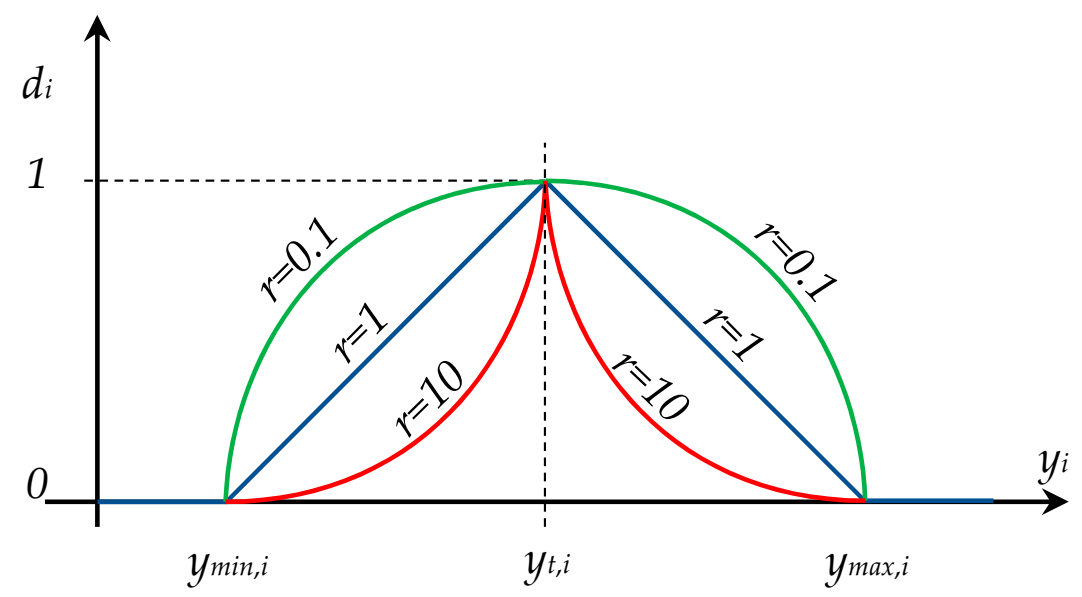

Figure A1. Desirability curves for a goal formulated in this case as "being equal to a target value"; if the assigned weight is 1 (default), the function is linear at both the sides of the target (stretch of the straight line); please note that the target value could even not be at the center of the interval.

\section{Appendix B. ANOVA Analysis for Each Response in the First Application of RSM}

The ANOVA was performed on each of the temperatures obtained from the CFD-FVM model, reported in Table 5 (31 n-tuples): $T_{1}$ (Table A1), $T_{2}$ (Table A2), $T_{3}$ (Table A3). For the significance of all reported statistical quantities, please see [75].

Table A1. ANOVA for the response surface reduced linear model concerning $T_{1}$ (1st dataset) before and after the backward selection process.

\begin{tabular}{cccccc}
\hline Source & Sum of Squares & df & Mean Square & F Value & $\begin{array}{c}p \text {-Value } \\
\text { Prob }>\text { F }\end{array}$ \\
\hline Model & $60,294.59$ & 8 & 7536.82 & 109.45 & $<0.0001$ \\
A-T & $27,117.89$ & 1 & $27,117.89$ & 393.82 & $<0.0001$ \\
B- $\dot{m}_{e x}$ & 5196.75 & 1 & 5196.75 & 75.47 & $<0.0001$ \\
C- $H_{h}$ & $16,622.82$ & 1 & $16,622.82$ & 241.40 & $<0.0001$ \\
D- $H_{e x}$ & $10,269.93$ & 1 & $10,269.93$ & 149.14 & $<0.0001$ \\
E- $e_{e x}$ & 423.92 & 1 & 423.92 & 6.16 & 0.0212 \\
F- $C_{r}$ & 47.89 & 1 & 47.89 & 0.70 & 0.4133 \\
G-C $C_{h}$ & 712.07 & 1 & 712.07 & 10.34 & 0.0040 \\
H- $e_{h}$ & 246.38 & 1 & 246.38 & 3.58 & 0.0718 \\
Residual & 1514.89 & 22 & 68.86 & & \\
Cor Total & $61,809.48$ & 30 & & & \\
\hline Model & $60,000.28$ & 6 & $10,000.05$ & 132.66 & $<0.0001$ \\
A-T & $27,106.06$ & 1 & $27,106.06$ & 359.58 & $<0.0001$ \\
B- $\dot{m}_{e x}$ & 5191.84 & 1 & 5191.84 & 68.87 & $<0.0001$ \\
C- $H_{h}$ & $16,607.16$ & 1 & $16,607.16$ & 220.30 & $<0.0001$ \\
D- $H_{e x}$ & $10,257.33$ & 1 & $10,257.33$ & 136.07 & $<0.0001$ \\
E- $e_{e x}$ & 422.03 & 1 & 422.03 & 5.60 & 0.0264 \\
G-C $C_{h}$ & 713.58 & 1 & 713.58 & 9.47 & 0.0052 \\
Residual & 1809.20 & 24 & 75.38 & & \\
Cor Total & $61,809.48$ & 30 & & & \\
\hline
\end{tabular}


Table A2. ANOVA for the response surface reduced linear model concerning $T_{2}$ (1st dataset) before and after the backward selection process.

\begin{tabular}{cccccc}
\hline Source & Sum of Squares & df & Mean Square & F Value & $\begin{array}{c}p \text {-Value } \\
\text { Prob }>\text { F }\end{array}$ \\
\hline Model & $78,970.18$ & 8 & 9871.27 & 252.65 & $<0.0001$ \\
A-T & $29,892.19$ & 1 & $29,892.19$ & 765.08 & $<0.0001$ \\
B- $\dot{m}_{e x}$ & 4284.20 & 1 & 4284.20 & 109.65 & $<0.0001$ \\
C- $H_{h}$ & 364.88 & 1 & 364.88 & 9.34 & 0.0058 \\
D- $H_{e x}$ & $31,505.45$ & 1 & $31,505.45$ & 806.37 & $<0.0001$ \\
E- $e_{e x}$ & 1586.85 & 1 & 1586.85 & 40.61 & $<0.0001$ \\
F-C $r$ & 55.51 & 1 & 55.51 & 1.42 & 0.2460 \\
G-C & 2.22 & 1 & 2.22 & 0.057 & 0.8136 \\
H- $e_{h}$ & 18.51 & 1 & 18.51 & 0.47 & 0.4984 \\
Residual & 859.56 & 22 & 39.07 & & \\
Cor Total & $79,829.74$ & 30 & & & \\
\hline Model & $78,893.81$ & 5 & $15,778.76$ & 421.47 & $<0.0001$ \\
A-T & $30,002.50$ & 1 & $30,002.50$ & 801.41 & $<0.0001$ \\
B- $\dot{m}_{e x}$ & 4296.54 & 1 & 4296.54 & 114.77 & $<0.0001$ \\
C- $H_{h}$ & 364.75 & 1 & 364.75 & 9.74 & 0.0045 \\
D- $H_{e x}$ & $31,722.68$ & 1 & $31,722.68$ & 847.36 & $<0.0001$ \\
E- $e_{e x}$ & 1595.03 & 1 & 1595.03 & 42.61 & $<0.0001$ \\
Residual & 935.93 & 25 & 37.44 & & \\
Cor Total & $79,829.74$ & 30 & & & \\
\hline
\end{tabular}

Table A3. ANOVA for the response surface reduced linear model concerning $T_{3}$ (1st dataset) before and after the backward selection process.

\begin{tabular}{cccccc}
\hline Source & Sum of Squares & df & Mean Square & F Value & $\begin{array}{c}p \text {-Value } \\
\text { Prob }>\text { F }\end{array}$ \\
\hline Model & $89,369.93$ & 8 & $11,171.24$ & 47.32 & $<0.0001$ \\
A-T & $63,320.82$ & 1 & $63,320.82$ & 268.23 & $<0.0001$ \\
B- $\dot{m}_{e x}$ & $10,594.21$ & 1 & $10,594.21$ & 44.88 & $<0.0001$ \\
$\mathrm{C}-H_{h}$ & 13.71 & 1 & 13.71 & 0.058 & 0.8118 \\
$\mathrm{D}-H_{e x}$ & 4321.88 & 1 & 4321.88 & 18.31 & 0.0003 \\
$\mathrm{E}-e_{e x}$ & 501.67 & 1 & 501.67 & 2.13 & 0.1590 \\
$\mathrm{~F}-C_{r}$ & 3.11 & 1 & 3.11 & 0.013 & 0.9096 \\
$\mathrm{G}-C_{h}$ & 31.47 & 1 & 31.47 & 0.13 & 0.7185 \\
$\mathrm{H}-e_{h}$ & 8.76 & 1 & 8.76 & 0.037 & 0.8490 \\
Residual & 5193.55 & 22 & 236.07 & & \\
Cor Total & $94,563.48$ & 30 & & & \\
\hline Model & $88,802.47$ & 3 & $29,600.82$ & 138.73 & $<0.0001$ \\
A-T & $65,998.97$ & 1 & $65,998.97$ & 309.32 & $<0.0001$ \\
B-m $\dot{m}_{e x}$ & $10,993.79$ & 1 & $10,993.79$ & 51.52 & $<0.0001$ \\
D- $H_{e x}$ & 4640.69 & 1 & 4640.69 & 21.75 & $<0.0001$ \\
Residual & 5761.01 & 27 & 213.37 & & \\
Cor Total & $94,563.48$ & 30 & & & \\
\hline
\end{tabular}

\section{Appendix C. ANOVA Analysis for Each Response in the Second Application of RSM}

The ANOVA was performed on each of the temperatures obtained from the CFD-FVM model, reported in Tables 5 and 8 (for a total of $61 n$-tuples): $T_{1}$ (Table A4), $T_{2}$ (Table A5), $T_{3}$ (Table A6). For the significance of all reported statistical quantities, please see [75]. 
Table A4. ANOVA for the response surface reduced linear model concerning $T_{1}$ (2nd dataset) before and after the backward selection process.

\begin{tabular}{cccccc}
\hline Source & Sum of Squares & df & Mean Square & F Value & $\begin{array}{c}p \text {-Value } \\
\text { Prob }>\text { F }\end{array}$ \\
\hline Model & $98,524.62$ & 8 & $12,315.58$ & 324.81 & $<0.0001$ \\
A-T & $34,012.71$ & 1 & $34,012.71$ & 897.05 & $<0.0001$ \\
B-m $\dot{m}_{e x}$ & $15,407.00$ & 1 & $15,407.00$ & 406.34 & $<0.0001$ \\
C- $H_{h}$ & $65,323.72$ & 1 & $65,323.72$ & 1722.85 & $<0.0001$ \\
D- $H_{e x}$ & $12,955.90$ & 1 & $12,955.90$ & 341.70 & $<0.0001$ \\
E- $e_{e x}$ & 1597.59 & 1 & 1597.59 & 42.13 & $<0.0001$ \\
F-C $C_{r}$ & 0.66 & 1 & 0.66 & 0.017 & 0.8958 \\
G-C $C_{h}$ & 2735.52 & 1 & 2735.52 & 72.15 & $<0.0001$ \\
H- $e_{h}$ & 56.92 & 1 & 56.92 & 1.50 & 0.2260 \\
Residual & 1971.64 & 52 & 37.92 & & \\
Cor Total & $1.005 \cdot 10^{5}$ & 60 & & & \\
\hline Model & $98,467.45$ & 6 & $16,411.24$ & 436.81 & $<0.0001$ \\
A-T & $35,159.09$ & 1 & $35,159.09$ & 935.82 & $<0.0001$ \\
B-m $\dot{m}_{e x}$ & $15,948.91$ & 1 & $15,948.91$ & 424.51 & $<0.0001$ \\
C- $H_{h}$ & $65,586.00$ & 1 & $65,586.00$ & 1745.68 & $<0.0001$ \\
D- $H_{e x}$ & $13,433.78$ & 1 & $13,433.78$ & 357.56 & $<0.0001$ \\
E- $e_{e x}$ & 1604.41 & 1 & 1604.41 & 42.70 & $<0.0001$ \\
G-C $C_{h}$ & 2910.00 & 1 & 2910.00 & 77.45 & $<0.0001$ \\
Residual & 2028.81 & 54 & 37.57 & & \\
Cor Total & $1.005 \cdot 10^{5}$ & 60 & & & \\
\hline
\end{tabular}

Table A5. ANOVA for the response surface reduced linear model concerning $T_{2}$ (2nd dataset) before and after the backward selection process.

\begin{tabular}{cccccc}
\hline Source & Sum of Squares & df & Mean Square & F Value & $\begin{array}{c}p \text {-Value } \\
\text { Prob }>\text { F }\end{array}$ \\
\hline Model & $80,413.35$ & 8 & $10,051.67$ & 478.27 & $<0.0001$ \\
A-T & $37,650.37$ & 1 & $37,650.37$ & 1791.44 & $<0.0001$ \\
B- $\dot{m}_{e x}$ & $12,515.28$ & 1 & $12,515.28$ & 595.49 & $<0.0001$ \\
C- $H_{h}$ & 1456.62 & 1 & 1456.62 & 69.31 & $<0.0001$ \\
D- $H_{e x}$ & $40,253.34$ & 1 & $40,253.34$ & 1915.29 & $<0.0001$ \\
E- $e_{e x}$ & 5770.08 & 1 & 5770.08 & 274.55 & $<0.0001$ \\
F-C & 0.90 & 1 & 0.90 & 0.043 & 0.8372 \\
G-C & 3.70 & 1 & 3.70 & 0.18 & 0.6763 \\
H- $e_{h}$ & 9.63 & 1 & 9.63 & 0.46 & 0.5014 \\
Residual & 1092.87 & 52 & 21.02 & & \\
Cor Total & $81,506.22$ & 60 & & & \\
\hline Model & $80,395.26$ & 5 & $16,079.05$ & 796.02 & $<0.0001$ \\
A-T & $38,763.81$ & 1 & $38,763.81$ & 1919.07 & $<0.0001$ \\
B- $\dot{m}_{e x}$ & $13,605.73$ & 1 & $13,605.73$ & 673.58 & $<0.0001$ \\
C- $H_{h}$ & 1583.19 & 1 & 1583.19 & 78.38 & $<0.0001$ \\
D- $H_{e x}$ & $42,108.25$ & 1 & $42,108.25$ & 2084.64 & $<0.0001$ \\
E- $e_{e x}$ & 6165.34 & 1 & 6165.34 & 305.23 & $<0.0001$ \\
Residual & 1110.96 & 55 & 20.20 & & \\
Cor Total & $81,506.22$ & 60 & & & \\
\hline
\end{tabular}


Table A6. ANOVA for the response surface reduced linear model concerning $T_{3}$ (2nd dataset) before and after the backward selection process.

\begin{tabular}{cccccc}
\hline Source & Sum of Squares & df & Mean Square & F Value & $\begin{array}{c}p \text {-Value } \\
\text { Prob }>\text { F }\end{array}$ \\
\hline Model & $1.125 \cdot 10^{5}$ & 8 & $14,062.02$ & 123.13 & $<0.0001$ \\
$\mathrm{~A}-T$ & $79,712.45$ & 1 & $79,712.45$ & 698.00 & $<0.0001$ \\
$\mathrm{~B}-\dot{m}_{e x}$ & $32,211.20$ & 1 & $32,211.20$ & 282.06 & $<0.0001$ \\
$\mathrm{C}-H_{h}$ & 1.17 & 1 & 1.17 & 0.010 & 0.9198 \\
$\mathrm{D}-H_{e x}$ & 6096.99 & 1 & 6096.99 & 53.39 & $<0.0001$ \\
$\mathrm{E}-e_{e x}$ & 152.70 & 1 & 152.70 & 1.34 & 0.2528 \\
$\mathrm{~F}-C_{r}$ & 5.92 & 1 & 5.92 & 0.052 & 0.8208 \\
$\mathrm{G}-C_{h}$ & 106.32 & 1 & 106.32 & 0.93 & 0.3391 \\
$\mathrm{H}-e_{h}$ & 36.11 & 1 & 36.11 & 0.32 & 0.5763 \\
Residual & 5938.47 & 52 & 114.20 & & \\
Cor Total & $1.184 \cdot 10^{5}$ & 60 & & & \\
\hline Model & $1.122 \cdot 10^{5}$ & 3 & $37,410.93$ & 343.83 & $<0.0001$ \\
A-T & $1.075 \cdot 10^{5}$ & 1 & $1.075 \cdot 10^{5}$ & 987.99 & $<0.0001$ \\
B-m $\dot{m}_{e x}$ & $44,398.97$ & 1 & $44,398.97$ & 408.06 & $<0.0001$ \\
D- $H_{e x}$ & 6725.32 & 1 & 6725.32 & 61.81 & $<0.0001$ \\
Residual & 6201.88 & 57 & 108.80 & & \\
Cor Total & $1.184 \cdot 10^{5}$ & 60 & & & \\
\hline
\end{tabular}

\section{References}

1. Karagulian, F.; Belis, C.A.; Dora, C.F.C.; Prüss-Ustün, A.M.; Bonjour, S.; Adair-Rohani, H.; Amann, M. Contributions to cities' ambient particulate matter (PM): A systematic review of local source contributions at global level. Atmos. Environ. 2015, 120, 475-483. [CrossRef]

2. Mcdonald, K. Air pollution in the urban atmosphere: Sources and consequences. In Metropolitan Sustainability: Understanding and Improving the Urban Environment, 1st ed.; Woodhead Publishing: Amsterdam, The Netherlands, 2012; pp. $231-259$.

3. Reitz, R.D.; Ogawa, H.; Payri, R.; Fansler, T.; Kokjohn, S.; Moriyoshi, Y.; Agarwal, A.; Arcoumanis, D.; Assanis, D.; Bae, C.; et al. IJER editorial: The future of the internal combustion engine. Int. J. Engine Res. 2020, 21, 3-10. [CrossRef]

4. Serrano, J. Imagining the Future of the Internal Combustion Engine for Ground Transport in the Current Context. Appl. Sci. 2017, 7, 1001. [CrossRef]

5. Kalghatgi, G.T. Developments in internal combustion engines and implications for combustion science and future transport fuels. Proc. Combust. Inst. 2015, 35, 101-115. [CrossRef]

6. Martins, J.; Brito, F.P. Alternative Fuels for Internal Combustion Engines. Energies 2020, 13, 4086. [CrossRef]

7. Bae, C.; Kim, J. Alternative fuels for internal combustion engines. Proc. Combust. Inst. 2017, 36, 3389-3413. [CrossRef]

8. Khan, T.M.Y. A Review of Performance-Enhancing Innovative Modifications in Biodiesel Engines. Energies $2020,13,4395$. [CrossRef]

9. Niculescu, R.; Clenci, A.; Iorga-Siman, V. Review on the Use of Diesel-Biodiesel-Alcohol Blends in Compression Ignition Engines. Energies 2019, 12, 1194. [CrossRef]

10. NCS-Newcarshop Bisogna Rinnovare Il Nostro Parco Auto Italiano [We Need to Renew Our Italian Car Fleet]. Available online: https: / / www.newcarshop.it/bisogna-rinnovare-il-parco-auto-italiano/ (accessed on 7 March 2021).

11. FEDERUNACOMA-Federazione Nazionale Costruttori Macchine per l'Agricoltura/Italian Agricultural Machinery Manufacturers Federation Annuari FEDERUNACOMA. Available online: http:/ / www.federunacoma.it/en/index.php (accessed on 7 March 2021).

12. Bietresato, M.; Calcante, A.; Mazzetto, F. A neural network approach for indirectly estimating farm tractors engine performances. Fuel 2015, 143, 144-154. [CrossRef]

13. FederUnacoma Audizione in Senato per FederUnacoma [Senate Hearing for FederUnacoma]. Available online: https://www. federunacoma.it/it/Audizione-in-Senato-per-FederUnacoma/n12209 (accessed on 7 March 2021).

14. Pala, S.G. Macchine Agricole: La Sicurezza Non è un Optional. Available online: https:/ /agronotizie.imagelinenetwork.com/ agrimeccanica/2019/02/14/macchine-agricole-la-sicurezza-non-e-un-optional/61760 (accessed on 7 March 2021).

15. ISO-International Organization for Standardization Standards Catalogue-ISO/TC 22/SC 3-Electrical and Electronic Equipment. Available online: http://www.iso.org/iso/home/store/catalogue_tc/home/store/catalogue_tc/catalogue_tc_browse. $\mathrm{htm}$ ?commid=46752\&published $=$ on (accessed on 7 March 2021).

16. Mazzetto, F.; Gallo, R.; Sacco, P. Reflections and Methodological Proposals to Treat the Concept of "Information Precision" in Smart Agriculture Practices. Sensors 2020, 20, 2847. [CrossRef] 
17. Srinivasa Rao, M.; Suresh Babu, E.; Siva Naga Raju, P.; Kavati, I. Smart Agriculture: Automated Controlled Monitoring System using Internet of Things. Int. J. Recent Technol. Eng. 2019, 8, 8778-8784.

18. Gurnule, P.V. Economical Smart Agriculture Monitoring System. Int. J. Recent Technol. Eng. 2019, 8, 3669-3671.

19. Ciruela-Lorenzo, A.M.; Del-Aguila-Obra, A.R.; Padilla-Meléndez, A.; Plaza-Angulo, J.J. Digitalization of Agri-Cooperatives in the Smart Agriculture Context. Proposal of a Digital Diagnosis Tool. Sustainability 2020, 12, 1325. [CrossRef]

20. Wan, J.; Cai, H.; Zhou, K. Industrie 4.0: Enabling technologies. In Proceedings of the 2015 International Conference on Intelligent Computing and Internet of Things, Harbin, China, 17-18 January 2015; pp. 135-140.

21. Mazzetto, F.; Gallo, R.; Importuni, P.; Petrera, S.; Sacco, P. Automatic filling of field activities register, from challenge into reality. Chem. Eng. Trans. 2017, 58, 667-672.

22. Shamim, S.; Cang, S.; Yu, H.; Li, Y. Management approaches for Industry 4.0: A human resource management perspective. In Proceedings of the 2016 IEEE Congress on Evolutionary Computation (CEC), Vancouver, BC, Canada, 24-29 July 2016; pp. 5309-5316.

23. Rodríguez-Molano, J.I.; Contreras-Bravo, L.E.; Rivas-Trujillo, E. Industry Knowledge Management Model 4.0. In Proceedings of the International Conference on Information Technology \& Systems (ICITS 2018). ICITS 2018. Advances in Intelligent Systems and Computing; Rocha, Á., Guarda, T., Eds.; Springer: Cham, Switzerland, 2018; pp. 275-283.

24. Candanedo, I.S.; Nieves, E.H.; González, S.R.; Martín, M.T.S.; Briones, A.G. Machine Learning Predictive Model for Industry 4.0. In Knowledge Management in Organizations. KMO 2018. Communications in Computer and Information Science; Uden, L., Hadzima, B., Ting, I., Eds.; Springer: Cham, Switzerland, 2018; pp. 501-510.

25. Çınar, Z.M.; Abdussalam Nuhu, A.; Zeeshan, Q.; Korhan, O.; Asmael, M.; Safaei, B. Machine Learning in Predictive Maintenance towards Sustainable Smart Manufacturing in Industry 4.0. Sustainability 2020, 12, 8211. [CrossRef]

26. Ghazikhani, M.; Hatami, M.; Safari, B.; Domiri Ganji, D. Experimental investigation of exhaust temperature and delivery ratio effect on emissions and performance of a gasoline-ethanol two-stroke engine. Case Stud. Therm. Eng. 2014, 2, 82-90. [CrossRef]

27. Singh, M.; Gandhi, S.K.; Mahla, S.K.; Sandhu, S.S. Experimental investigations on performance and emission characteristics of variable speed multi-cylinder compression ignition engine using Diesel/Argemone biodiesel blends. Energy Explor. Exploit. 2018, 36, 535-555. [CrossRef]

28. Elkelawy, M.; Alm-Eldin Bastawissi, H.; Esmaeil, K.K.; Radwan, A.M.; Panchal, H.; Sadasivuni, K.K.; Ponnamma, D.; Walvekar, R. Experimental studies on the biodiesel production parameters optimization of sunflower and soybean oil mixture and DI engine combustion, performance, and emission analysis fueled with diesel/biodiesel blends. Fuel 2019, 255, 115791. [CrossRef]

29. Wu, G.; Ge, J.C.; Choi, N.J. A Comprehensive Review of the Application Characteristics of Biodiesel Blends in Diesel Engines. Appl. Sci. 2020, 10, 8015. [CrossRef]

30. Vargas, F.; Pérez, A.; Delgado, R.; Hernández, E.; Suástegui, J.A. Performance Analysis of a Compression Ignition Engine Using Mixture Biodiesel Palm and Diesel. Sustainability 2019, 11, 4918. [CrossRef]

31. Mirbagheri, S.A.; Safieddin Ardebili, S.M.; Kiani Deh Kiani, M. Modeling of the engine performance and exhaust emissions characteristics of a single-cylinder diesel using nano-biochar added into ethanol-biodiesel-diesel blends. Fuel 2020, $278,118238$. [CrossRef]

32. Valencia Ochoa, G.; Acevedo Peñaloza, C.; Duarte Forero, J. Combustion and Performance Study of Low-Displacement Compression Ignition Engines Operating with Diesel-Biodiesel Blends. Appl. Sci. 2020, 10, 907. [CrossRef]

33. Kee, R.J.; Hung, P.; Fleck, B.; Irwin, G.; Kenny, R.; Gaynor, J.; McLoone, S. Fast Response Exhaust Gas Temperature Measurement in IC Engines. In SAE Technical Papers; SAE International: Troy, MI, USA, 2006; Volume 115, pp. 598-609.

34. Heywood, J.B. Internal Combustion Engine Fundamentals, 2nd ed.; McGraw-Hill Education: New York, NY, USA, 2018.

35. De Souza, E.G.; Milanez, L.F. Indirect evaluation of the torque of diesel engines. Trans. ASAE 1988, 31, 1350-1354. [CrossRef]

36. Karami, R.; Rasul, M.G.; Khan, M.M.K.; Anwar, M. Performance analysis of direct injection diesel engine fueled with diesel-tomato seed oil biodiesel blending by ANOVA and ANN. Energies 2019, 12, 4421. [CrossRef]

37. Çay, Y.; Çiçek, A.; Kara, F.; Sağiroğlu, S. Prediction of engine performance for an alternative fuel using artificial neural network. Appl. Therm. Eng. 2012, 37, 217-225. [CrossRef]

38. Najafi, B.; Faizollahzadeh Ardabili, S.; Mosavi, A.; Shamshirband, S.; Rabczuk, T. An Intelligent Artificial Neural NetworkResponse Surface Methodology Method for Accessing the Optimum Biodiesel and Diesel Fuel Blending Conditions in a Diesel Engine from the Viewpoint of Exergy and Energy Analysis. Energies 2018, 11, 860. [CrossRef]

39. Jaliliantabar, F.; Ghobadian, B.; Najafi, G.; Yusaf, T. Artificial Neural Network Modeling and Sensitivity Analysis of Performance and Emissions in a Compression Ignition Engine Using Biodiesel Fuel. Energies 2018, 11, 2410. [CrossRef]

40. Alkidas, A.C.; Battiston, P.A.; Kapparos, D.J. Thermal Studies in the Exhaust System of a Diesel-Powered Light-Duty Vehicle. In SAE Technical Papers; SAE International: Troy, MI, USA, 2004; Volume 113, pp. 164-181.

41. Kapparos, D.J.; Foster, D.E.; Rutland, C.J. Sensitivity Analysis of a Diesel Exhaust System Thermal Model. In SAE Technical Papers; SAE International: Troy, MI, USA, 2004.

42. Cavina, N. Measurement of Exhaust Gas Temperatures: Theoretical and Experimental Analysis. In ASME ICE 2002 Fall Technical Conference; ASME: New Orleans, LA, USA, 2002; pp. 1-9.

43. Fortunato, F.; Caprio, M.; Oliva, P.; D’Aniello, G.; Pantaleone, P.; Andreozzi, A.; Manca, O. Numerical and Experimental Investigation of the Thermal Behavior of a Complete Exhaust System. In SAE Technical Papers; SAE International: Troy, MI, USA, 2007; Volume 2007. 
44. Kee, R.J.; O’Reilly, P.G.; Fleck, R.; McEntee, P.T. Measurement of Exhaust Gas Temperatures in a High Performance Two-Stroke Engine. In SAE Technical Papers; SAE International: Troy, MI, USA, 1998; Volume 107, pp. 2413-2423.

45. Zhang, X.; Romzek, M. Computational Fluid Dynamics (CFD) Applications in Vehicle Exhaust System. In SAE Technical Papers; SAE International: Troy, MI, USA, 2008; Volume 2008, pp. 776-790.

46. Brito, C.H.G.; Maia, C.B.; Sodré, J.R. A Mathematical Model for the Exhaust Gas Temperature Profile of a Diesel Engine. J. Phys. Conf. Ser. 2015, 633, 012075. [CrossRef]

47. Rony, R.U.; Hasan, N.; Ashiqur, M.; Laskar, R. Heat Transfer of Pulsating Turbulent Flow in Pipes. Eur. J. Adv. Eng. Technol. 2018, $5,511-516$.

48. Fernández-Yáñez, P.; Armas, O.; Gómez, A.; Gil, A. Developing Computational Fluid Dynamics (CFD) Models to Evaluate Available Energy in Exhaust Systems of Diesel Light-Duty Vehicles. Appl. Sci. 2017, 7, 590. [CrossRef]

49. Bannister, C.D.; Brace, C.J.; Taylor, J.; Brooks, T.; Fraser, N. The use of multi-variate models for the prediction of heat transfer in vehicle exhaust systems. Proc. Inst. Mech. Eng. Part D J. Automob. Eng. 2010, 224, 369-385. [CrossRef]

50. Kohler, Co. Lombardini Motori by Kohler. Available online: https://kohlerpower.com/en/engines (accessed on 7 March 2021).

51. Soft-Engine Soft-Engine Dynamometers. Available online: http:/ / www.soft-engine.org/ (accessed on 7 March 2021).

52. Bietresato, M.; Renzi, M.; Mischiatti, S.; Mazzetto, F. Engine test stand layout and post processing tools for the detection of many engine performance parameters. ARPN J. Eng. Appl. Sci. 2016, 11, 1309-1316.

53. Natonal Instruments National Instruments Corp. Available online: www.ni.com/en-us.html (accessed on 7 March 2021).

54. Joint Committee for Guides in Metrology. JCGM 100:2008 Evaluation of Measurement Data-Guide to the Expression of Uncertainty in Measurement; JCGM: Sèvres, France, 2008.

55. Sobachkin, A.; Dumnov, G.; Sobachkin, A. Numerical Basis of CAD-Embedded CFD. In Proceedings of NAFEMS World Congress 2013; NAFEMS: Salzburg, Austria, 2013.

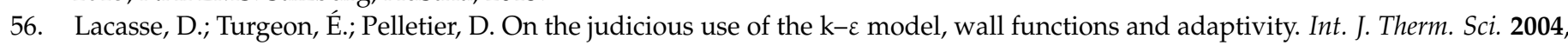
43, 925-938. [CrossRef]

57. Dassault Systèmes SolidWorks Corporation. Enhanced Turbulence Modeling in SolidWorks Flow Simulation. In MKTURBMODWPENG0313; SolidWorks: Waltham, MA, USA, 2013; pp. 1-21.

58. Van Driest, E.R. On Turbulent Flow Near a Wall. J. Aeronaut. Sci. 1956, 23, 1007-1011. [CrossRef]

59. Jääskeläinen, H. Diesel Exhaust Gas. Available online: https:/ /dieselnet.com/tech/diesel_exh.php\#temp (accessed on 7 March 2021).

60. Mattarelli, E.; Rinaldini, C.; Savioli, T. Combustion Analysis of a Diesel Engine Running on Different Biodiesel Blends. Energies 2015, 8, 3047-3057. [CrossRef]

61. Attar, H.M.; Wu, D.; Harvey, A.P. Performance, Emissions and Durability Studies on Diesel Engine Fuelled with a Preheated Raw Microalgal Oil. Proceedings 2020, 58, 4. [CrossRef]

62. Incropera, F.P.; DeWitt, D.P. Fundamentals of Heat and Mass Transfer; John Wiley \& Sons, Inc.: Hoboken, NJ, USA, 1996.

63. Tera Analysis Ltd. Quickfield-Natural Convection Coefficient Calculator. Available online: https://quickfield.com/natural_ convection.htm (accessed on 7 March 2021).

64. Bright Hub, PM. Natural Convection Heat Transfer Coefficient Estimation Calculations. Available online: https://www. brighthubengineering.com/hvac/92660-natural-convection-heat-transfer-coefficient-estimation-calculations / (accessed on 7 March 2021).

65. Madhusudana, C.V. Thermal Contact Conductance; Mechanical Engineering Series; Springer International Publishing: Cham, Switzerland, 2014.

66. Box, G.E.P.; Wilson, K.B. On the Experimental Attainment of Optimum Conditions. J. R. Stat. Soc. Ser. B 1951, 13, 1-45. [CrossRef]

67. Montgomery, D.C. Design and Analysis of Experiments. John Wiley \& Sons: Hoboken, NJ, USA, 2013 ; Volume 2.

68. Bezerra, M.A.; Santelli, R.E.; Oliveira, E.P.; Villar, L.S.; Escaleira, L.A. Response surface methodology (RSM) as a tool for optimization in analytical chemistry. Talanta 2008, 76, 965-977. [CrossRef] [PubMed]

69. Bietresato, M.; Sartori, L. Technical aspects concerning the detection of animal waste nutrient content via its electrical characteristics. Bioresour. Technol. 2013, 132, 127-136. [CrossRef]

70. Bietresato, M.; Pavan, S.; Cozzi, G.; Sartori, L. A numerical approach for evaluating and properly setting self-propelled forage harvesters. Trans. ASABE 2013, 56, 5-14. [CrossRef]

71. Bietresato, M.; Carabin, G.; Vidoni, R.; Mazzetto, F.; Gasparetto, A. A parametric approach for evaluating the stability of agricultural tractors using implements during side-slope activities. Contemp. Eng. Sci. 2015, 8, 1289-1309. [CrossRef]

72. Bietresato, M.; Caligiuri, C.; Bolla, A.; Renzi, M.; Mazzetto, F. Proposal of a Predictive Mixed Experimental- Numerical Approach for Assessing the Performance of Farm Tractor Engines Fuelled with Diesel-Biodiesel-Bioethanol Blends. Energies 2019, $12,2287$. [CrossRef]

73. Stat-Ease. StatEase-Statistics Made Easy. Available online: https:/ /www.statease.com/ (accessed on 7 March 2021).

74. Neter, J.; Kutner, M.H.; Nachtsheim, C.J.; Wasserman, W. Applied Linear Statistical Models, 4th ed.; WCB McGraw-Hill: New York, NY, USA, 1996.

75. Myers, R.H.; Montgomery, D.C. Response Surface Methodology: Process and Product in Optimization Using Designed Experiments, 1st ed.; John Wiley \& Sons, Inc.: Hoboken, NJ, USA, 1995.

76. Derringer, G.; Suich, R. Simultaneous Optimization of Several Response Variables. J. Qual. Technol. 1980, 12, 214-219. [CrossRef] 
77. Press, W.H.; Vetterling, W.T.; Teukolsky, S.A.; Vetterling, W.T. Numerical Recipes in Pascal: The Art of Scientific Computing; Cambridge University Press: New York, NY, USA, 1989.

78. Dalvand, M.J.; Mohtasebi, S.S.; Rafiee, S. Optimization on drying conditions of a solar electrohydrodynamic drying system based on desirability concept. Food Sci. Nutr. 2014, 2, 758-767. [CrossRef]

79. Rabiee, M.; Zandieh, M.; Jafarian, A. Scheduling of a no-wait two-machine flow shop with sequence-dependent setup times and probable rework using robust meta-heuristics. Int. J. Prod. Res. 2012, 50, 7428-7446. [CrossRef] 